\title{
The year in cardiology: heart failure \\ The year in cardiology 2019
}

John G.F. Cleland ${ }^{*, \# \dagger, \text { Alexander R. Lyon }}{ }^{\#, \neq}$, Theresa McDonagh ${ }^{\jmath, \infty}$ and John J.V. McMurray ${ }^{\dagger}$

SAHeart 2020; 17:30-47

"Robertson Centre for Biostatistics and Clinical Trials, University of Glasgow, Glasgow, United Kingdom

\#National Heart \& Lung Institute, Imperial College, London, United Kingdom

†British Heart Foundation Cardiovascular Research Centre, University of Glasgow, Glasgow, United Kingdom

‡Royal Brompton Hospital, London, United Kingdom

'King's College Hospital, London, United Kingdom

`King's College London, London, United Kingdom

Address for correspondence:

John G.F. Cleland

Robertson Centre for Biostatistics and Clinical Trials

University of Glasgow

Glasgow GI2 8QQ

United Kingdom

Email:

John.Cleland@glasgow.ac.uk

\section{INTRODUCTION}

The past year has brought many new concepts and an abundance of new data on the nature, management, and outcome of heart failure. The pace of change is accelerating. We look forward to an exciting new decade of research. The prognosis of cardiovascular disease is determined to a large extent by the ability to delay or prevent the development and progression of heart failure.(') Accordingly, attention is shifting to earlier diagnosis of and intervention for heart failure. Patients with type-2 diabetes mellitus (T2DM) (2) or coronary artery disease $(C A D)^{(3)}$ have a relatively good prognosis unless plasma concentrations of natriuretic peptides are increased, indicating important cardiac or renal dysfunction. Adoption of a simple "Universal Definition" of heart failure based on natriuretic peptides would facilitate early diagnosis and treatment but lead to an enormous increase in its prevalence and demand upon medical services. ${ }^{(4)}$ We need to prepare for the impending shock.

\section{EPIDEMIOLOGY AND PREVENTION}

In cardiology, the term prevention is often used to mean delaying the onset of disease; in other words, procrastination. Failure to appreciate the difference between prevention and procrastination leads to problems in projecting future healthcare needs and costs. Older people have more co-morbid conditions that complicate management but may also offer more opportunities for intervention; consequently, more time and resources are required to manage older patients well.

A detailed report on heart failure in the UK shows that the median age of onset has risen to about 80 years, consistent with improvements in the treatment of hypertension and other risk factors for atherosclerosis and better management of myocardial infarction.(5) Unfortunately, data on left ventricular ejection fraction (LVEF) were not available for this report. Analyses of the diagnostic pathway in primary care in the UK suggest that key investigations are often not done. ${ }^{(6-8)}$ Similar data from other countries are urgently required. Several large epidemiological surveys $s^{(9,10)}$ and analyses of large trials ${ }^{(1,1,12)}$ have recently been published that allow the demographics, aetiology, and management of heart failure to be compared internationally.

Mineralocorticoid receptor antagonists (MRAs) are effective anti-hypertensive agents that also improve the prognosis of patients with heart failure and a reduced (HFrEF) and possibly preserved (HFpEF) LVEF.(13) Whether MRAs have specific effects on reducing other potential drivers of the progression to heart failure such as inflammation and fibrosis is currently under investigation..$^{(14,15)}$ Genetic propensity to greater body fat was associated with the risk of developing heart failure in an analysis on 367703 UK Biobank participants. ${ }^{(16)}$ However, the incidence of heart failure was only 1\% (4 803 patients), the diagnostic criteria were not robust, and the increase in risk was modest (odds ratio 1.22; 95\% Cl 1.06 - 1.4I). Further analyses on this population showed a strong relationship between cardio-respiratory fitness and grip strength and future incidence of heart failure. ${ }^{(17)}$ A study of 4403 people considered for bariatric surgery in Sweden and followed for 22 years, found that I 88 (9\%) of the 2003 who had surgery $(25-35 \mathrm{~kg}$ weight loss; BMI I year after surgery $32 \mathrm{~kg} / \mathrm{m}^{2}$ ) developed heart failure compared with 266 (13\%) of 2030 who did not (BMI after I year observation $\left.40 \mathrm{~kg} / \mathrm{m}^{2}\right)$. ${ }^{(18)}$ Although these data suggest links between obesity and the risk of developing heart failure, it is possible that obesity just provokes similar symptoms. Once heart failure has developed, obesity is associated with a lower 
mortality, but this may also reflect earlier diagnosis rather than a protective effect. (19) Randomised controlled trials (RCTs) of effective interventions for obesity are required to demonstrate whether weight loss improves symptoms (likely) and clinical outcomes (less certain).

A report from "the Atherosclerosis Risk in Communities" (ARIC) study confirmed the association between influenza epidemics and hospitalisations for heart failure, reinforcing guideline-recommendations for vaccination;(20) an RCT is underway. ${ }^{(21)}$ Extended follow-up (median 18.9years) of the Women's Health Initiative Hormone Therapy trials, which randomised 27347 women to various hormone replacement regimens, showed that they had no effect on the incidence of HFrEF or PEF.(22) The ISCHAEMIA trial (presented at the American Heart Association 2019) compared strategies of early coronary revascularisation, predominantly percutaneous, with conservative management for stable CAD, some of whom had mild symptoms of heart failure and/or a reduced LVEF. Revascularisation did not reduce the risk of myocardial infarction or death, but increased the risk of stroke almost four-fold and did not reduce new-onset heart failure over the following 4 years.

\section{DIAGNOSIS}

The Heart Failure Association of the European Society of Cardiology has proposed a new scoring system for the diagnosis of HFpEF.(23) Its practical utility awaits confirmation. ${ }^{(24)}$ Simpler approaches may be preferred. ${ }^{(4)}$

\section{CONGESTION}

Congestion lies at the heart of failure.(25-27) Imaging has long been used to identify dilation of the atria and venous system, which might be termed haemodynamic congestion, for which natriuretic peptides are a useful biomarker.(25) More recently, imaging has been used to identify accumulation of fluid in tissues (tissue congestion), (25,28-32) which may be associated with increases in the biomarker, (bio)-adrenomedullin. ${ }^{(33)}$ Imaging and biomarkers in combination are both sensitive and specific for detecting a failing heart, a useful guide to the severity of congestion and prognosis and a potential therapeutic target indicating successful management. Imaging remains the preferred method for identifying the cause of heart failure. If congestion is central to the management of heart failure, then better monitoring ${ }^{(34)}$ and more effective (diuretic) interventions (perhaps acetazolamide?) $)^{(35)}$ should improve outcome (Figure I).

\section{AGE AND PROGNOSIS}

Analysis of a large primary care database suggested that the cardiovascular (CV) prognosis of new-onset heart failure improved substantially between 2002 and 2014 [hazard ratio (HR): $0.73 ; 95 \% \mathrm{Cl} 0.68$ - 0.80] for patients above and below the age of 80 years. ${ }^{(5)}$ However, in those aged $>80$ years, the fall in CV mortality was entirely offset by non-CV mortality. In other words, treatment changed the way that elderly patients died but not overall mortality (Figure 2). Unfortunately, information on LVEF was not available; many patients will have had HFpEF and, therefore, caution should be exercised in attributing the reduction in $\mathrm{CV}$ mortality to treatment of heart failure. A systematic review of survey and registry data also suggested that the prognosis of heart failure had improved; important determinants of outcome were age and cardiology input to management. ${ }^{(36)}$ Frailty, which might be considered a biological rather than a chronological measure of age, may be an even more powerful predictor of disability and death. ${ }^{(37)}$ Guideline-recommendations for the treatment of HFrEF do not discriminate by age. The Swedish Heart Failure Registry found that prescription of ACE inhibitors or beta-blockers to patients with HFrEF aged $>80$ years was associated with a lower mortality. ${ }^{(38,39)}$ However, observational associations have many explanations other than a therapeutic effect. ${ }^{(40)}$ An individual patient-data meta-analysis of 3 RCTs of MRA (RALES, EMPHASIS, and TOPCAT-Americas) (13) suggested that MRAs exerted similar reductions in mortality (by about $\sim 25 \%$ ) for patients with HFrEF above and below age 75 years, but benefit was less certain for HFpEF.

\section{THE DIVERSITY OF HEART FAILURE PHENOTYPES}

Precision-medicine, which should also be accurate, requires patients to be classified in a way that informs management. For oncology, this has focused on the genetic cause, tumour location, and spread. For heart failure, a multi-system disorder, it is much more complex. ${ }^{(41-47)}$ Current, therapeutically relevant classifications of heart failure include the severity of congestion (based on symptoms, signs, blood biomarkers, and imaging), CAD, heart rate and rhythm and QRS duration, blood pressure, serum potassium, renal function, indices of iron deficiency, mitral regurgitation, infiltrative myocardial disease (e.g. amyloid), and ventricular phenotype. ${ }^{(41,48)}$ Optimal management of heart failure, with a few rare exceptions, requires only a modest amount of information, but this still creates many thousands of patient-subgroups or clusters that might have different therapeutic needs. ${ }^{(45,46)}$ Such subgroups will increase exponentially with the introduction of each new class of treatment. Despite this heterogeneity of substrate and wealth of interventions, precision-medicine is in its infancy in heart failure.

One therapeutically relevant classification of heart failure is by LVEF, a surrogate for left ventricular (LV) dilation. Prior to the 1980s, imaging of cardiac function was available only in expert centres. Clinical trials relied on the chest $\mathrm{X}$-ray rather 


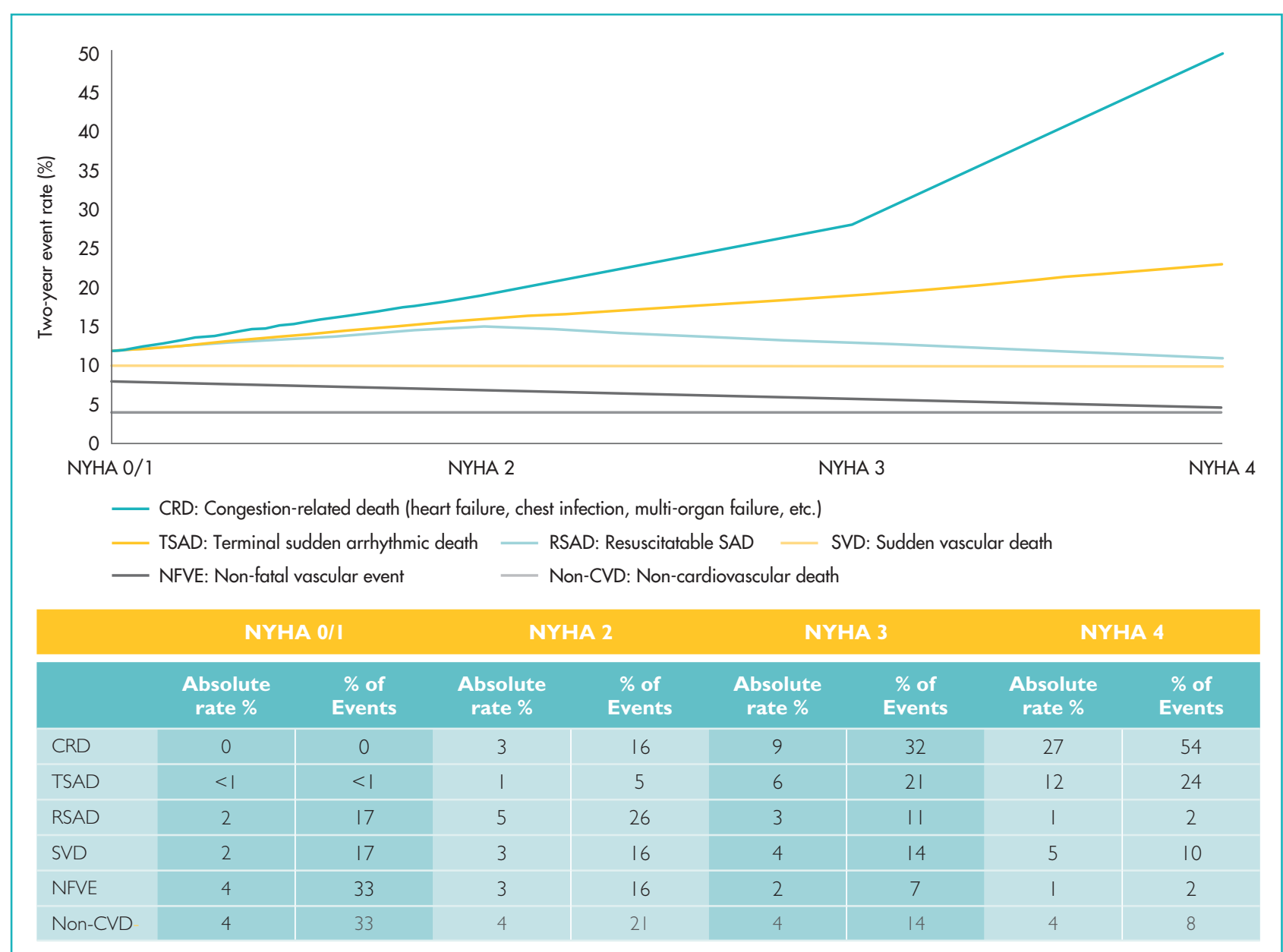

FIGURE I: Two-year cause-specific mortality and non-fatal vascular events for patients with cardiovascular disease according to New York Heart Association (NYHA) class.

Numbers and proportions are a conceptual representation of absolute and relative risk and are not strictly evidence-based. Note that for patients in NYHA Class 4, interventions for sudden arrhythmic death may be ineffective or fail to lead to a meaningful prolongation of life because the patient is likely soon to die of worsening heart failure. CRD, congestion-related death, otherwise called death due to worsening heart failure; NFVE, non-fatal vascular event (e.g. myocardial infarction and stroke; note that events are more likely to be suddenly fatal as heart failure progresses); non-CVD, non-cardiovascular death; RSAD, resuscitatable sudden arrhythmic death; SVD, sudden vascular death; TSAD, terminal (non-resucitatable) sudden arrhythmic death. Reproduced with permission from ref. ${ }^{(59)}$

than the echocardiogram to support a diagnosis of heart failure. The success of trials such as SOLVD, MERIT, and CHARM, which all had a reduced LVEF as an inclusion criterion, led to the adoption of LVEF $<40 \%$ as the European Society of Cardiology (ESC) Guideline definition for HFrEF.(49) Values $240 \%$ were termed HFpEF, comprising patients with a mid-range or mildly-reduced (HFmrEF), normal (HFnEF) and, perhaps, supra-normal (HFsnEF) LVEF.(50) Analyses of $>350000$ routinely collected echocardiograms suggested that the nadir of risk, whether or not the patient has a diagnosis of heart failure, lies in the range $60 \%-65 \%$ both for men and women. Interestingly, an LVEF of $>70 \%$ was associated with

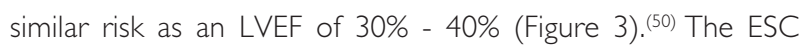
Guidelines of 2016 introduced the concept of HFmrEF, for 2 main reasons. Firstly, because of imprecision, an echocardio- graphic measurement could not reliably distinguish between 2 measurements of LVEF within 10\% of each other. Creating a buffer-zone between HFrEF and HFnEF meant that misclassification was less likely. This innovation meant that a trial of HFpEF could not claim benefit for all patients with an LVEF $>40 \%$ based solely on an effect in those with an LVEF $40 \%$ $49 \%$. Secondly, the introduction of HFmrEF challenged the convention that an LVEF $<40 \%$ was the correct threshold for HFrEF. Some analyses subsequent to the ESC 2016 Guideline suggest that patients with an LVEF $<50 \%$ may respond to treatment similarly to those with an LVEF $<40 \% .{ }^{(51)}$ However, this interpretation could reflect confirmation-bias amongst enthusiastic proponents of HFmrEF (Table I). The evidence is not so consistent when looked at in its entirety, especially if mortality is considered a key outcome. In the future, many trials 


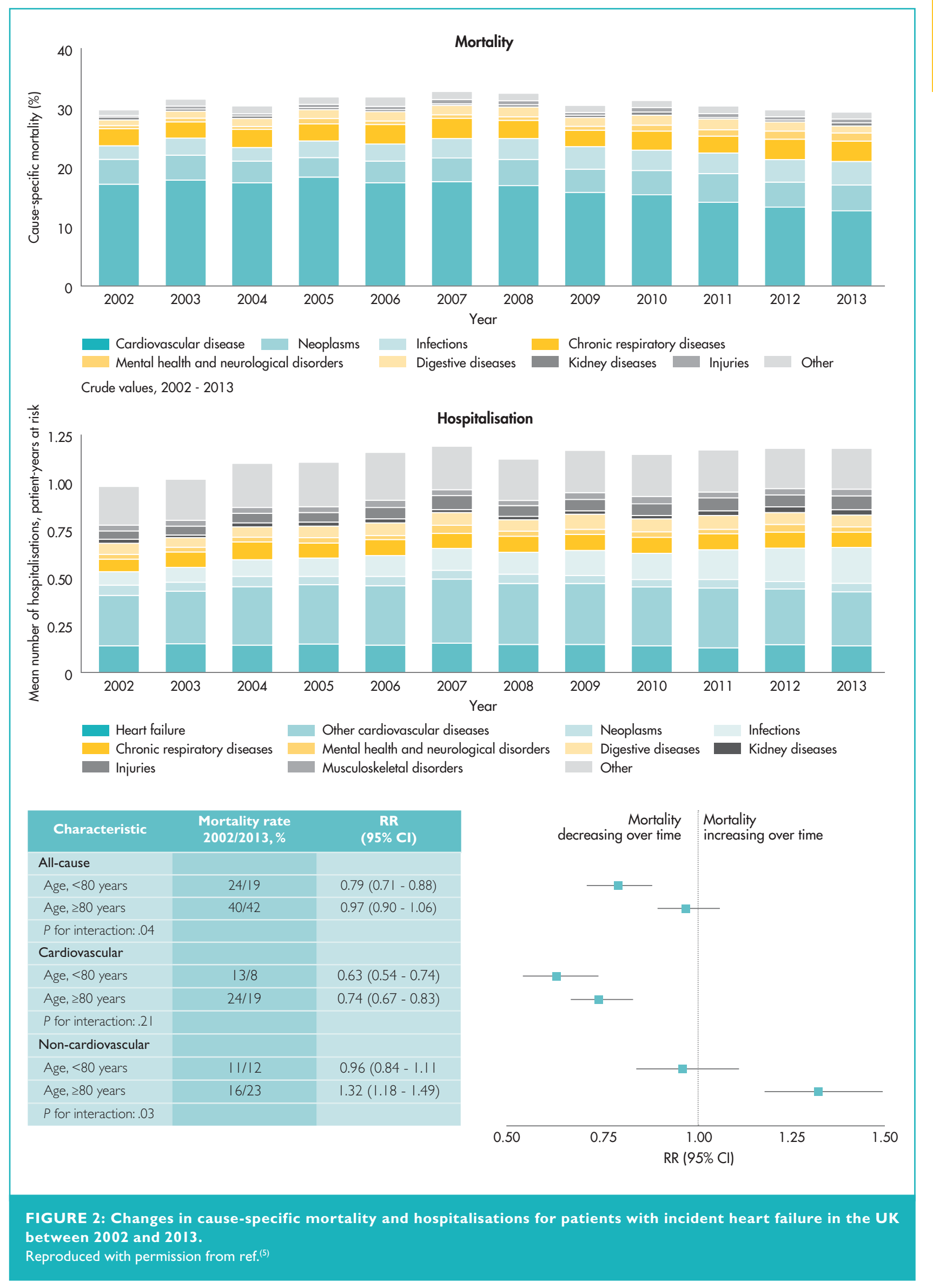




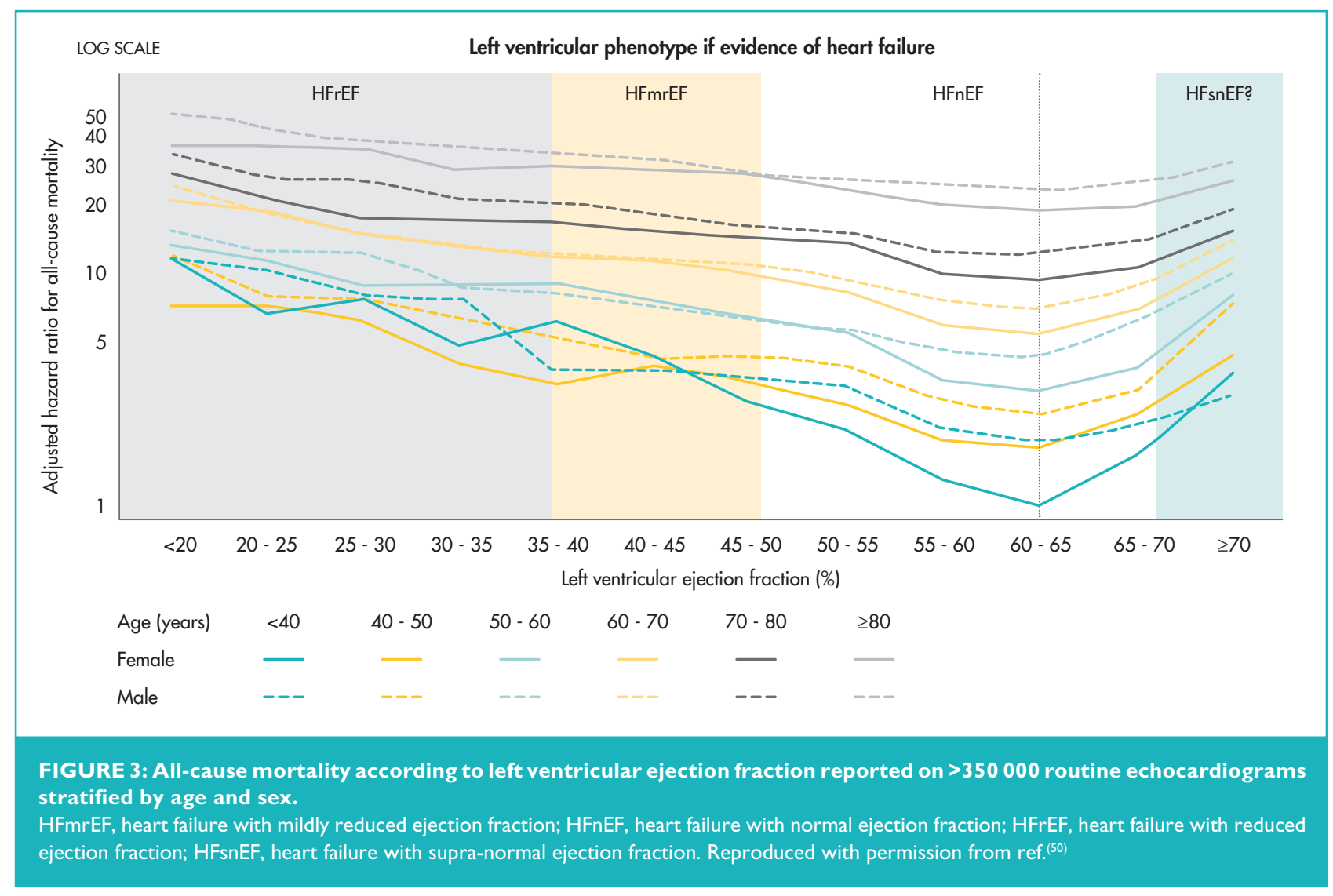

will probably include both HFrEF and HFmrEF, others will include HFmrEF, HFnEF, and HFsnEF, but NT-proBNP should be used routinely to stratify risk and potentially exclude lowrisk patients who have little to gain from yet another "pill'. Assuming we continue to use LVEF to classify patients, which seems likely since we cannot undo the past, then the major issue is where to set thresholds. For HFrEF, these have ranged from $<25 \%$ in COPERNICUS, $<30 \%$ in MADIT-II and RAFT to $<35 \%-40 \%$ for the bulk of other trials. ${ }^{(51)}$ For HFpEF, LVEF has generally been set at $>40 \%$ or $>45 \%$ with no upper limit. Analyses of recent trials have led some to suggest that, for patients with an elevated NT-proBNP, the upper limit of LVEF for HFmrEF should be increased to $55 \%$ or even $60 \%$, but this seems premature until consistency is demonstrated across multiple interventions and end-points and measurement precision for LVEF improves.

In a substantial observational study of patients with HFpEF and pulmonary hypertension, progression of right rather than left ventricular dysfunction was observed and was associated with an increased risk of atrial fibrillation (AF) and death. ${ }^{(52)}$ Although right ventricular (RV) dysfunction is a powerful prognostic marker, remarkably few trials focusing on RV dysfunction have been done (SERENADE: https://clinicaltrials. gov/ct2/show/NCT031531। I).

\section{ATRIAL FIBRILLATION}

About a third of outpatients, perhaps more for those with HFpEF, (53) and more than half of those admitted with heart failure will be in AF, which is associated with an adverse prognosis even after correcting for age and other risk factors. ${ }^{(54)}$ Controversy continues over whether medical management focused on rate control or restoration of sinus rhythm is the better strategy for AF and heart failure. In practice, the strategy needs to be tailored to the patient. When AF is the driver of symptoms and worsening cardiac function, restoration of sinus rhythm might be appropriate but when AF reflects the progression of underlying cardiac dysfunction, it may not. ${ }^{(55)}$ For new-onset or paroxysmal AF associated with a clear deterioration in symptoms, restoration of sinus rhythm may be warranted to improve symptoms. For long-standing AF and heart failure with markedly dilated atria, sustained restoration of sinus rhythm and atrial contraction is less likely. Optimal pharmacological management includes anticoagulation, avoiding toxic anti-arrhythmic agents and lenient ventricular rate control. Beta-blockers are the agent of choice for rate control, a resting day-time ventricular rate of $70-90 \mathrm{bpm}$ is preferred, ${ }^{(49)}$ which may require only modest doses; digoxin should be used sparingly, if at all. Unfortunately, RCTs of rate vs. rhythm control for AF have failed to optimise the rate control strategy in the above fashion. 
A meta-analysis of RCTs of rate vs. rhythm control included 4 trials $(n=2486)$ comparing pharmacological rhythm to rate control found no difference in mortality or thromboembolic events but an increase in hospitalisations, often due to recurrent $A F$, in the rhythm control group. ${ }^{(56)}$ Six trials $(n=|| \mid 2)$ comparing AF ablation with rate control reported reductions in mortality $(0.5 \mathrm{I} ; 95 \% \mathrm{Cl} 0.36-0.74)$, hospitalisations $(0.44$; $95 \% \mathrm{Cl} 0.26-0.76)$, and stroke $(0.59: 95 \% \mathrm{Cl} 0.23-1.5 \mathrm{I})$, and an improved quality of life. ${ }^{(56)}$ However, none of the trials individually had a robust result, patients were highly selected and the rate control strategy was not optimal. As such, this meta-analysis should be considered hypothesis generating. Further trials are required with greater involvement of heart failure physicians.

\section{IMPLANTED ELECTRICAL DEVICES}

The controversy over the role of high-energy devices for heart failure continues. Long-term follow-up of cardiac resynchronisation therapy (CRT) in a French Registry showed a low rate of sudden death amongst patients who received CRT-Pacing (without a defibrillator). ${ }^{(57-59)}$ A systematic review of observational studies and RCTs reported that differences in the rate of sudden death with CRT-Pacing and CRT-D were narrow- ing. ${ }^{(58)}$ RCTs comparing CRT-Pacing and CRT-D are underway ${ }^{(59)}$ (Figure I). Whether myocardial scar found on cardiac magnetic resonance imaging identifies patients with more to gain from an implantable cardioverter defibrillator (ICD) is also under investigation ${ }^{(60)}$ (CMR_GUIDE; https://clinicaltrials.gov/ ct2/show/NCT01918215). Retrospective analysis of SCDHeFT found that patients with T2DM did not benefit from an ICD. ${ }^{(61)}$ An individual patient-data meta-analysis confirmed a reduction in sudden death with MRA. ${ }^{(62)}$ A systematic review identified 22 studies with post-mortem interrogation of ICDs; the analysis suggested that $24 \%$ of sudden deaths were not arrhythmic. ${ }^{(63)}$ A substantial multi-point pacing trial failed, so far, to show improvements in the clinical or echocardiographic response to CRT. ${ }^{(64)}$

\section{MITRAL REGURGITATION}

COAPT suggested that a percutaneously delivered mitral clip could reduce functional (secondary) regurgitation with a subsequent substantial improvement in morbidity and mortality that was moderately cost-effective in a US healthcare context (US\$40 361 per life-year gained and $\$ 55600$ per qualityadjusted life year).(65-68) Two-year follow-up of MITRA.fr

TABLE I: Evidence supporting or refuting the benefits of treatments for heart failure with a left ventricular ejection fraction in the "mid-range" (HFmrEF: 40\% - 49\%).

\begin{tabular}{|c|c|c|c|c|c|c|}
\hline & LVEF & Symptoms & $\begin{array}{l}\text { Hospitalisation } \\
\text { for heart failure }\end{array}$ & $\begin{array}{l}\mathrm{CV} \text { death or } \\
\mathrm{HFH}^{\mathrm{a}}\end{array}$ & CV mortality & $\begin{array}{l}\text { All-cause } \\
\text { mortality }\end{array}$ \\
\hline \multicolumn{7}{|l|}{ Diuretics } \\
\hline Perindopril & & Improved & & $0.38(0.19-0.75)^{\mathrm{b}}$ & & \\
\hline Candesartan & & Improved & $0.72(0.55-0.95) \Pi$ & $0.76(0.61-0.96)$ & $0.81(0.60-1.11)$ & $0.79(0.60-1.04)$ \\
\hline Irbesartan & & & & $0.98(0.85-1.12) \Delta$ & & \\
\hline ARNI (Sac/Nal) vs. Valc & & Improved & $0.77(0.58-1.02)$ & $0.81(0.64-1.03)$ & $0.94(0.69-1.28)$ & NYR \\
\hline MRA (overall) $)^{c}$ & & & $0.76(0.46-1.27)$ & $0.72(0.50-1.05)$ & $0.69(0.43-1.12)$ & $0.73(0.49-1.10)$ \\
\hline MRA (Americas) $^{c}$ & & & $0.60(0.32-1.10)$ & $0.55(0.33-0.91)$ & $0.46(0.23-0.94)$ & $0.58(0.34-0.99)$ \\
\hline B-Blocker (SR) & Improved & & $0.95(0.68-1.32)$ & $0.83(0.60-1.13)$ & $0.48(0.24-0.97)$ & $0.59(0.34-1.03)$ \\
\hline B-Blocker (AF) & Improved & & $1.15(0.57-2.32)$ & $1.06(0.58-1.94)$ & $0.86(0.36-2.03)$ & $1.30(0.63-2.67)$ \\
\hline \multicolumn{7}{|l|}{ Ivabradine } \\
\hline Digoxin & & & $0.80(0.63-1.03)$ & $0.96(0.79-1.17)$ & $1.24(0.94-1.64)$ & $1.08(0.85-1.37)$ \\
\hline Rivaroxaban vs. aspirin & & & $0.65(0.40-1.05)$ & & & $0.75(0.53-1.06)$ \\
\hline Rivaroxaban+Aspirin vs. aspirin & & & $0.87(0.56-1.35)$ & & & $0.63(0.44-0.90)$ \\
\hline \multicolumn{7}{|l|}{ CRT } \\
\hline \multicolumn{7}{|l|}{$I C D$} \\
\hline BNP-guided therapy & & & & $\begin{array}{l}\text { Reduction from } \\
67 \% \text { - } 44 \% \text { patients } \\
\text { with an event }\end{array}$ & & \\
\hline
\end{tabular}

Statistically significant results are shown in bold on a white background. Blank cells indicate no relevant information reported. Other data shown are not significant, although may not be heterogeneous with the effect in patients with a reduced left ventricular ejection fraction (HFrEF). Data for sacubitril/valsartan taken from reference for LVEF $>42.5 \%-52.5 \% .{ }^{(98)}$

$A F=$ atrial fibrillation, $A R N I=$ angiotensin receptor-neprilysin inhibitors, $B N P=$ brain natriuretic peptide, $C R T=$ cardiac resynchronisation therapy, $I C D=i m p l a n t a b l e ~ c a r d i o v e r t e r$ defibrillator, $L V E F=$ left ventricular ejection fraction, $M R A=$ Mineralocorticoid receptor antagonist, $S R=$ sinus rhythm.

aRecurrent event analyses used when available.

${ }^{b}$ The PEP-CHF trial specified inclusion of patients with LVEF $40 \%-49 \%$ as was LVEF $>49 \%$ but did not report effects in this subgroup. However, it did report effects in patients with a prior myocardial infarction who were more likely to have HFmrEF.

stronger effect in women. 
suggested no benefit. ${ }^{\left({ }^{69}\right)}$ A possible explanation for the apparent discrepancy could be the ratio of the severity of $L V$ dysfunction to the severity of mitral regurgitation. When regurgitation is disproportionate to the severity of LV dysfunction it may drive disease progression and correction may improve outcome. ${ }^{(70.71)}$ When regurgitation is proportionate to the severity of LV dysfunction, fixing the mitral regurgitation may be less useful because myocardial dysfunction drives disease progression. The concept is simple and plausible, but application in practice may be difficult. Mitral regurgitation offloads the LV and may mask dysfunction. It is also likely that there is a spectrum of primary and secondary mitral regurgitation, with some patients having a mixed picture. More experience and further data from RCTs may improve patient selection (RESHAPE-HF2: https://clinicaltrials.gov/ct2/show/NCT 02444338). However, optimising guideline-recommended therapy, including diuretic dose, may cause mitral regurgitation secondary to dilation of the LV and mitral ring to improve or resolve. Other technologies for secondary mitral ${ }^{(72)}$ and tricuspid regurgitation ${ }^{(73,74)}$ are being developed.

\section{CORONARY ARTERY DISEASE}

In COMPASS ( $n=27$ 395), 5902 with CAD, in sinus rhythm and with a diagnosis of heart failure (predominantly HFpEF) were randomly assigned to aspirin $100 \mathrm{mg} /$ day, rivaroxaban $5 \mathrm{mg}$ bd or aspirin and rivaroxaban $2.5 \mathrm{mg}$ bd. ${ }^{(75,76)}$ The study was stopped early for benefit on the primary endpoint (a composite of CV death, stroke, or myocardial infarction) with the combination compared with aspirin alone. Further analysis suggested a reduction in all-cause mortality for patients with heart failure, especially HFpEF, assigned to combination therapy (HR: 0.63; $0.44-0.90$ ) or rivaroxaban alone (HR: 0.75; 0.53 l.06) with an estimated $4 \%$ absolute difference at 2 years; rather similar to the magnitude of effect in HFrEF for sacubitrilvalsartan(77) or dapagliflozin ${ }^{(78)}$ (Figure 4). This suggests that coronary events might be an important driver of death in HFpEF (Figure I), although effects of rivaroxaban on endothelial function, inflammation, and fibrosis should not be discounted. The analysis also suggests that those who do not have heart failure have little to gain from additional treatment with rivaroxaban.

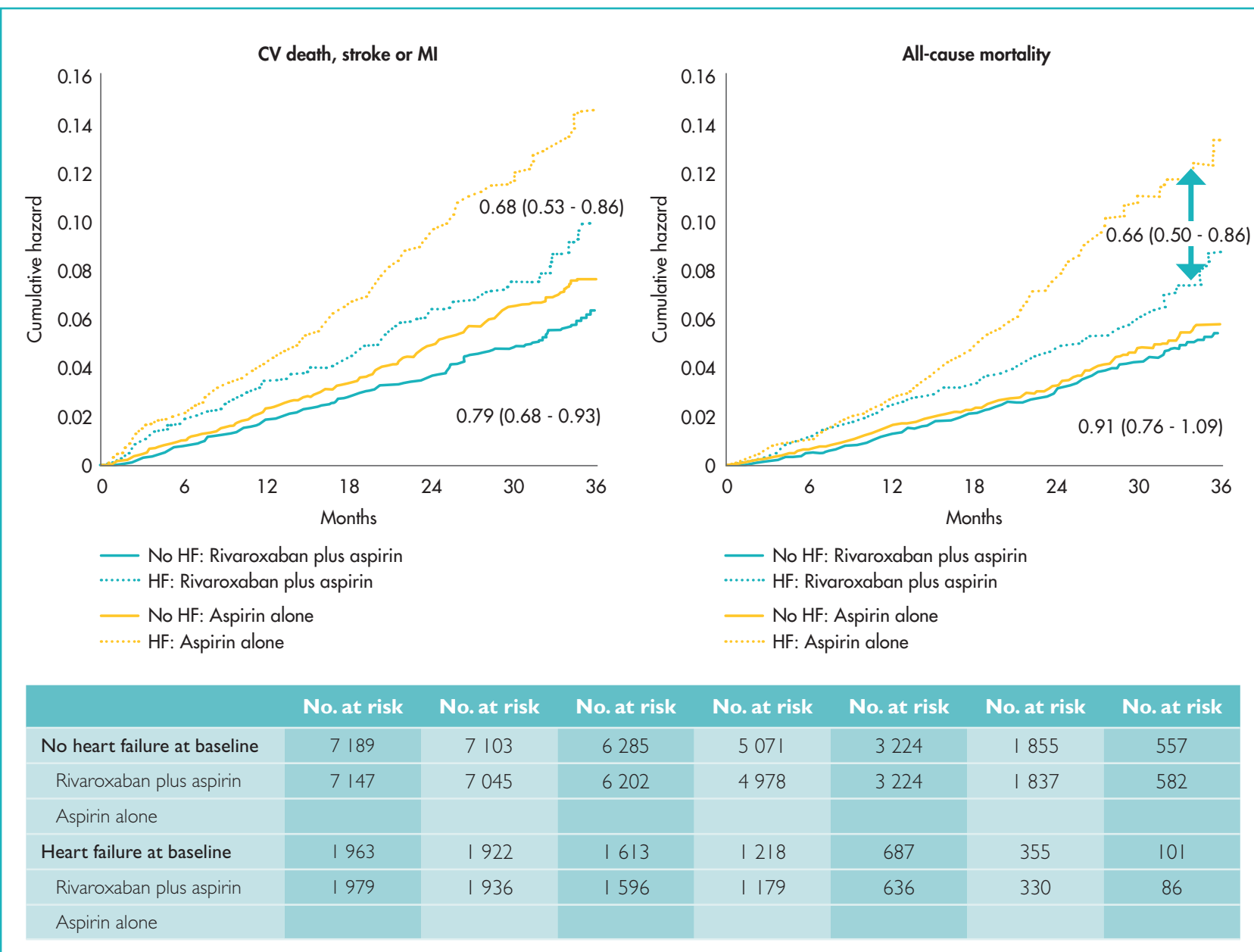

FIGURE 4: Effect of rivaroxaban $2.5 \mathrm{mg}$ bd and aspirin $100 \mathrm{mg} /$ day compared with aspirin alone for stable CAD, sinus rhythm and heart failure (predominantly heart failure with preserved ejection fraction) in COMPASS-HF. Reproduced with permission from ref. ${ }^{(75)}$ 
However, for patients with HFrEF, CAD in sinus rhythm with a recent hospital discharge for worsening heart failure, addition of rivaroxaban $2.5 \mathrm{mg}$ bd to background anti-platelet therapy did not improve overall prognosis, although a composite of vascular outcomes (stroke, myocardial infarction, and sudden death) was reduced, driven mainly by a reduction in stroke. ${ }^{(79,80)}$ This suggests that for patients with stable CAD and more advanced heart failure, hospitalisations, and deaths due to worsening heart failure are not greatly influenced by anti-thrombotic therapy (Figure I).

\section{ANGIOTENSIN RECEPTOR-NEPRILYSIN INHIBITORS}

\section{Heart failure with reduced ejection fraction}

As experience in the implementation of angiotensin receptorneprilysin inhibitors (ARNIs) grows, both in clinical trials and in clinical practice, there is a strong argument to consider them as first-line agents, rather than angiotensin converting-enzyme inhibitors (ACEi) or angiotensin receptor blockers (ARB), for the treatment of HFrEF. In PIONEER-HF, ${ }^{(8)}{ }^{88}$ I patients with an LVEF $\leq 40 \%$ who were hospitalised for worsening heart failure were randomly assigned, without a run-in period, to sacubitril/valsartan or enalapril prior to discharge and followed for 8 weeks to determine the effect on plasma concentrations of NT-proBNP; about one-third had new-onset heart failure. Sacubitril-valsartan exerted a greater reduction in NT-proBNP. Reductions in markers of myocardial injury or stress, highsensitivity cardiac troponin-T and soluble ST2, were also observed. These effects appeared early after randomisation (within I - 4 weeks). Moreover, patients assigned to sacubitril/ valsartan were less likely to experience adverse outcomes within the first 8 weeks. TRANSITION ${ }^{(82)}$ randomly assigned I 002 patients to pre- or post-discharge initiation of sacubitril/valsartan, showing no adverse consequences to earlier administration.

EVALUATE ${ }^{(83)}$ compared the effects of sacubitril/valsartan and enalapril on aortic stiffness in HFrEF most of whom were already chronically treated with an ACEi or ARB. After 24 weeks treatment, no differences in aortic stiffness were observed, but slightly greater reductions in LV end-diastolic and systolic volumes were observed with sacubitril/valsartan compared with enalapril, although changes in LVEF were similar. Mitral E-velocity and left atrial volume declined, consistent with a fall in left atrial pressure. PROVE-HF, ${ }^{(84)}$ an observational study, had similar findings and showed that most of the decline in NT-proBNP occurred within 14 days consistent with the rapid onset of clinical benefit observed with sacubitril/valsartan in trials and clinical practice. PRIME ${ }^{(85)}$ was an RCT $(n=1 \mid 8)$ comparing the effects of sacubitril/valsartan or valsartan on functional mitral regurgitation in patients with an LVEF between
$25 \%$ and $49 \%$ who were already receiving an ACEi or ARB. Those assigned to sacubitril/valsartan had greater reductions in mitral regurgitation and LV end-diastolic and left atrial volumes, but LVEF increased by a similar small amount in each group (about 2.5\%).

Further reports from PARADIGM-HF suggest that, compared with enalapril, sacubitril/valsartan may improve markers of collagen metabolism, in particular, decreasing synthesis of type-I collagen, which makes an important contribution to myocardial stiffness. ${ }^{(86)}$ In I-PRESERVE, irbesartan (an ARB) did not affect collagen biomarkers compared with placebo. ${ }^{(87)}$

\section{Heart failure with preserved ejection fraction}

PARAGON-HF investigated the effect of sacubitril/valsartan compared to valsartan alone on morbidity and mortality in patients with HFpEF (defined as an LVEF >45\%). ${ }^{(88)}$ It was the first $\mathrm{RCT}$ since PEP-CHF ${ }^{\left({ }^{89}\right)}$ to require patients to be treated with diuretics, the first-line treatment for the relief of symptoms and signs of congestion, and to have echocardiographic evidence of cardiac dysfunction. It was also the first large trial of HFpEF to require all patients to have raised plasma concentrations of natriuretic peptides, the most powerful, widely available prognostic marker in HFpEF. Sacubitril/valsartan was compared with valsartan rather than placebo, because many patients eligible for PARAGON-HF had indications for ACE inhibitors and ARBs such as hypertension and CAD. The only trial comparing valsartan to placebo in HFpEF was of modest size and neutral. ${ }^{(90)}$ Previous RCTs of other ARBs, including candesartan (CHARM-Preserved) and irbesartan (I-PRESERVE) failed to show substantial benefit for HFpEF. ${ }^{(88)}$ Patients had to tolerate, sequentially, both valsartan and sacubitril/valsartan at half the intended target dose before randomisation. This simulates clinical practice (doctors do not usually prescribe medicines to patients unwilling or unable to take them) and reduces the risk of a neutral trial-outcome due to low adherence. Of 10539 patients screened, 4822 were randomised.

PARAGON-HF was neutral for its primary endpoint (CV death or the total number of recurrent hospitalisations for heart failure; ${ }^{(91)}$ Figure 5). Some have argued that the $p$-value was very close to 0.05 and that it was "almost" positive. This misses the point. The trial shows that the size of the potential benefit of sacubitril/valsartan for HFpEF is modest, regardless of the p-value and that the treatment is, overall, unlikely to be cost-effective. Accordingly, we should look for more effective treatments or, more controversially, subgroups that obtain greater benefit. After a median follow-up of 35 months, 23\% of patients experienced a primary event, but the annual incidence of CV and all-cause mortality were, respectively, only about $3 \%$ and $5 \%$, which is similar to those for previous trials of HFpEF and for elderly patients with resistant hypertension 


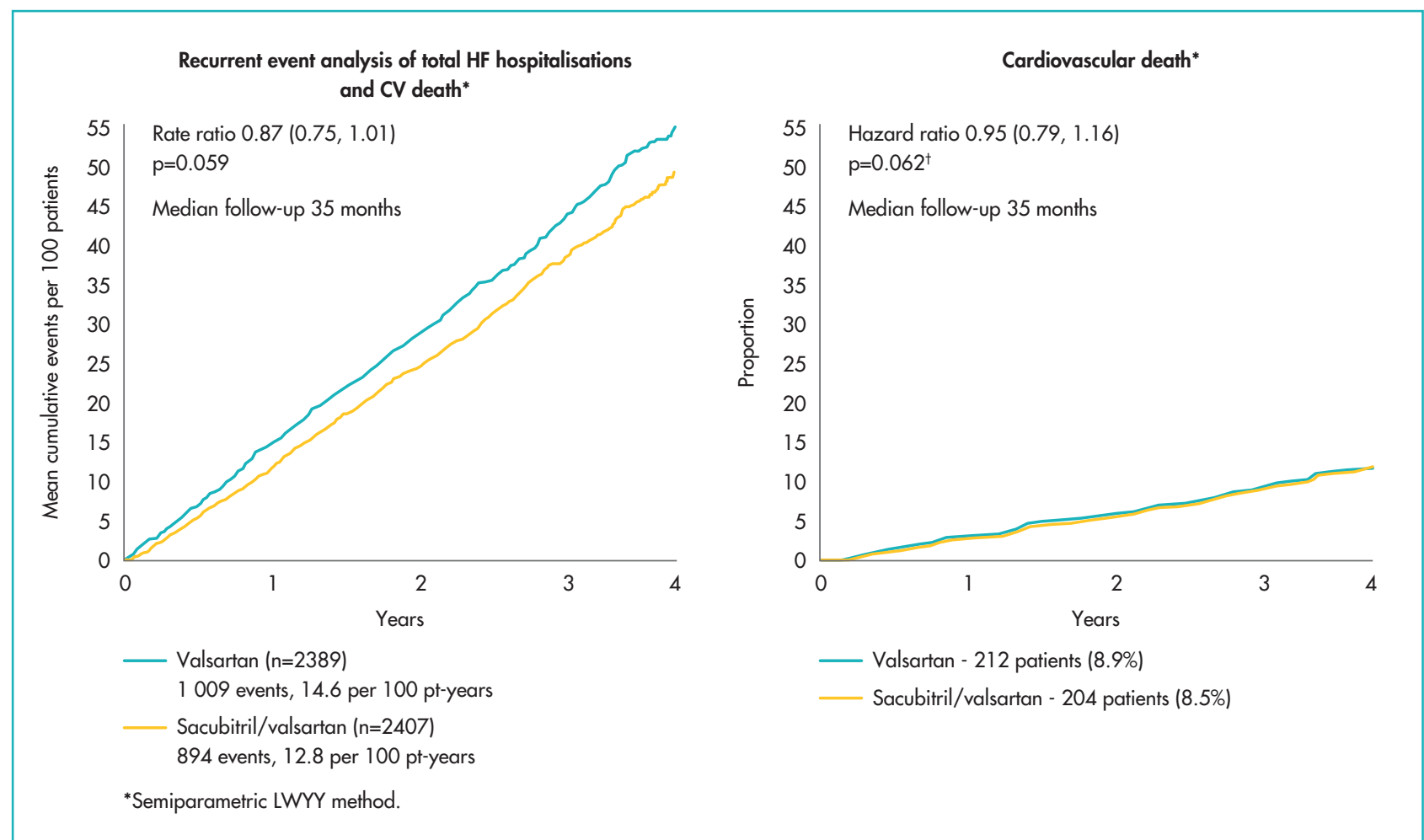

FIGURE 5: Effect of sacubitril/valsartan compared with valsartan for heart failure with preserved ejection fraction in PARAGON-HF.

Reproduced with permission from ref.(91)

assigned to placebo in HYVET.(92) Although $<3 \%$ of patients were reported to have heart failure in HYVET, a combination of indapamide and perindopril reduced all-cause mortality and cut the incidence of heart failure by $>50 \%$. Many of these patients probably had undiagnosed HFpEF prior to randomisation. Higher rates of hospitalisation for heart failure in trials of HFpEF compared to hypertension may well reflect ascertainment bias, as clinicians who are interested or expert in the management of heart failure are more likely to diagnose or report heart failure events. Overall, these trials suggest that the mortality rate and possibly the rates of cardiovascular and all-cause hospitalisation may be similar in patients with and without a diagnosis of HFpEF, if they have a similar burden of co-morbidities. However, it is also likely that many patients with hypertension, CAD and T2DM have undiagnosed heart failure.

Subgroup analysis suggested that the effect of sacubitril/valsartan on the primary endpoint was greater for patients with an LVEF below the median (57\%), but this was driven almost entirely by an effect on hospitalisation for heart failure rather than on CV death. ${ }^{(93)}$ The effect of sacubitril/valsartan on the primary endpoint was also greater for women and this was true throughout the studied range of LVEF, but again this was driven by a difference in hospitalisation for heart failure and not CV mortality. ${ }^{\left({ }^{4}\right)}$ Reductions in NT-proBNP were similar for each sex. Sacubitril/valsartan appeared to have a favourable effect on quality of life for men, but not for women. Patients with a recent heart failure hospitalisation may also have benefited more. ${ }^{(95)}$ These observations should be interpreted in the light of a trial that was neutral for its primary endpoint. No effect was observed on mortality and the benefits of treatment on quality of life and hospitalisations for heart failure according to sex were inconsistent. In PARADIGM-HF, no difference in treatment effect according to sex was observed. A further sizeable RCT in HFpEF, PARALLAX-HF, investigating the effects of sacubitril/valsartan on quality of life and exercise capacity will provide more evidence in 2020 (https:// clinicaltrials.gov/ct2/show/NCT03066804).

\section{DO WOMEN AND MEN RESPOND DIFFERENTLYTOTREATMENT?}

An analysis of 12058 patients with HFrEF in 2 large trials found that women had more severe symptoms, similar LVEF but a substantially better prognosis than men, even after adjusting for key prognostic variables including aetiology and NT-proBNP (HR: 0.68; 0.62 - 0.89). ${ }^{(96)}$ A combined analysis of PARAGON$\mathrm{HF}$ and PARADIGM-HF suggested that patients with HFrEF and HFpEF had similarly impaired quality of life, but that women 
generally reported a worse quality of life than men. ${ }^{(97)}$ In an observational analysis of patients with HFrEF, the BIOSTAT survey also found that women generally had a better prognosis than men, despite being prescribed lower doses of betablockers and ACE inhibitors. ${ }^{(98)}$ Interestingly, men and women had the same heart rate, the pharmacodynamic marker of beta-blocker dose. For patients with HFpEF in the TOPCAT trial, reductions in mortality, but not hospitalisations for heart failure, were greater for women, although the interaction was statistically significant only for all-cause mortality. ${ }^{(99)}$ In the PARAGON-HF trial (HFpEF), women obtained greater benefit than men throughout the studied range of LVEF, but the difference was driven by differences in the rate of hospitalisation for heart failure rather than mortality. ${ }^{(94)}$ One obvious difference between men and women, on average, is size. Cardiac resynchronisation therapy is reputed to be more effective in women than men, but differences disappear once adjusted for height. ${ }^{(100)}$ Many medicines are cleared by the kidney. Estimated glomerular filtration rate (eGFR) is indexed to body surface area (BSA), but doses of treatment are usually not. A woman (or small man) weighing $64 \mathrm{~kg}$ and $160 \mathrm{~cm}$ tall has BSA of $1.67 \mathrm{~m}^{2}$ using the Dubois formula and a man (or large woman) weighing $85 \mathrm{~kg}$ and $180 \mathrm{~cm}$ tall has a BSA $2.05 \mathrm{~m}^{2}$. If both have an eGFR of $60 \mathrm{~mL} / \mathrm{kg} / \mathrm{m}^{2}$, then the woman (or small man) has an un-indexed eGFR of $100 \mathrm{~mL} / \mathrm{min}$ and the man (or large woman) has an un-indexed eGFR of $123 \mathrm{~mL} / \mathrm{min}$. If a medicine is cleared by the kidney then perhaps smaller people require lower doses to achieve the same plasma therapeutic concentration and clinical benefit?

\section{SODIUM-GLUCOSE COTRANSPORTER-2 INHIBITORS}

Sodium-glucose cotransporter protein-2 (SGLT2) is found mainly in the proximal renal tubule and to a lesser extent in other organs. SGLTI is abundant in the intestine and myocardium. SGLT2 inhibitors (SGLT2i) cause glycosuria, improving glycaemia, which led to their development for the treatment of T2DM, and an osmotic diuresis, leading to a contraction of plasma volume. ${ }^{(10,102)}$ SGLTI inhibitors reduce intestinal glucose absorption, which can cause diarrhoea, but might have favourable effects on myocardial energy-utilisation. ${ }^{(103)}$ Most SGLT2i are highly selective, including dapagliflozin and empagliflozin, but sotagliflozin is less selective. ${ }^{(103)}$ EMPA-REG enrolled 7020 patients with T2DM, about 10\% of whom had heart failure (LVEF was not measured) and showed that empagliflozin reduced the risk of hospitalisation for heart failure and mortality. ${ }^{(104)}$ Within a few weeks of initiating empagliflozin, body weight, and blood pressure fell and haematocrit rose, consistent with a diuretic effect. Subsequent RCTs of other SGLT2i in T2DM had similar findings. Meta-analyses suggested that SGLT2i were the hypoglycaemic agents most likely to reduce incident heart failure, ${ }^{(105-107)}$ while observational data raises concerns about insulin therapy. ${ }^{(108)}$ A meta-analysis of RCTs of empagliflozin, canagliflozin, and dapagliflozin for T2DM, including >30 000 patients, showed benefit, at least for those with established CV disease.(109) For the outcome of hospitalisation for heart failure or CV death, the annual rate was about $0.6 \%$ for the 13672 patients with multiple risk factors, but without established CV disease, about 3\% for the 20650 patients with established atherosclerotic disease and about $6 \%$ for 3891 patients with heart failure at baseline; the relative risk reductions with $\mathrm{SGLT} 2 \mathrm{i}$ in these populations were $16 \%, 24 \%$, and $29 \%$, respectively, without evidence of heterogeneity amongst agents. The largest of these trials, DECLARE,(110) included 17160 patients of whom 67। had HFrEF and I 316 had HFpEF or an unspecified LVEF. In a subgroup analysis, (111) dapagliflozin reduced hospitalisations for heart failure and CV mortality for HfrEF, but not for other patient-groups (Figure 6).

DAPA-HF(78,112) enrolled 4744 patients and followed them for a median of 18.3 months, demonstrating that addition of dapagliflozin to guideline-recommended therapy for HFrEFreduced hospitalisations for heart failure by $30 \%$ and mortality (mainly cardiovascular) by 18\%, preventing 3 - 5 hospitalisations and I - 2 deaths per 100 patients treated per year (Figure 7). Patients were somewhat less likely to experience serious adverse events, especially renal, with dapagliflozin compared with placebo. The benefits appeared consistent across subgroups, although patients with evidence of more severe congestion (worse NYHA class or higher NT-proBNP) may have received less benefit. Importantly, benefits were similar for those with and without T2DM and regardless of age.(113) Dapagliflozin also improved quality of life, ${ }^{(1 / 4)}$ an effect that was confirmed in a smaller RCT (DEFINE) $)^{(115)}$ that followed 263 patients for 12 weeks; about one in 6 patients got a meaningul benefit, either prevention of worsening or an improvement in symptoms, compared with placebo.

In DAPA-HF, the placebo-corrected decline in weight between baseline and 8 months was $0.87 \mathrm{~kg}$ and this was associated with a small fall in NT-proBNP and systolic blood pressure and a small increase in haematocrit and serum creatinine. These findings are again consistent with the belief that SGLT2i exert at least some of their benefits by enhancing diuresis, either through an osmotic effect of glycosuria or by interfering with sodium-hydrogen exchange in the nephron. ${ }^{(116)}$ The effects of SGLT2i appear early, consistent with an immediate haemodynamic effect. However, alternative or additional explanations for the effect of SGLT2i have been proposed. A small RCT suggested that empagliflozin stimulated production of erythropoietin leading to a rise in haematocrit and a fall in ferritin, a marker of inflammation and iron deficiency, although not transferrin saturation, a marker of iron deficiency alone. ${ }^{(117)}$ 


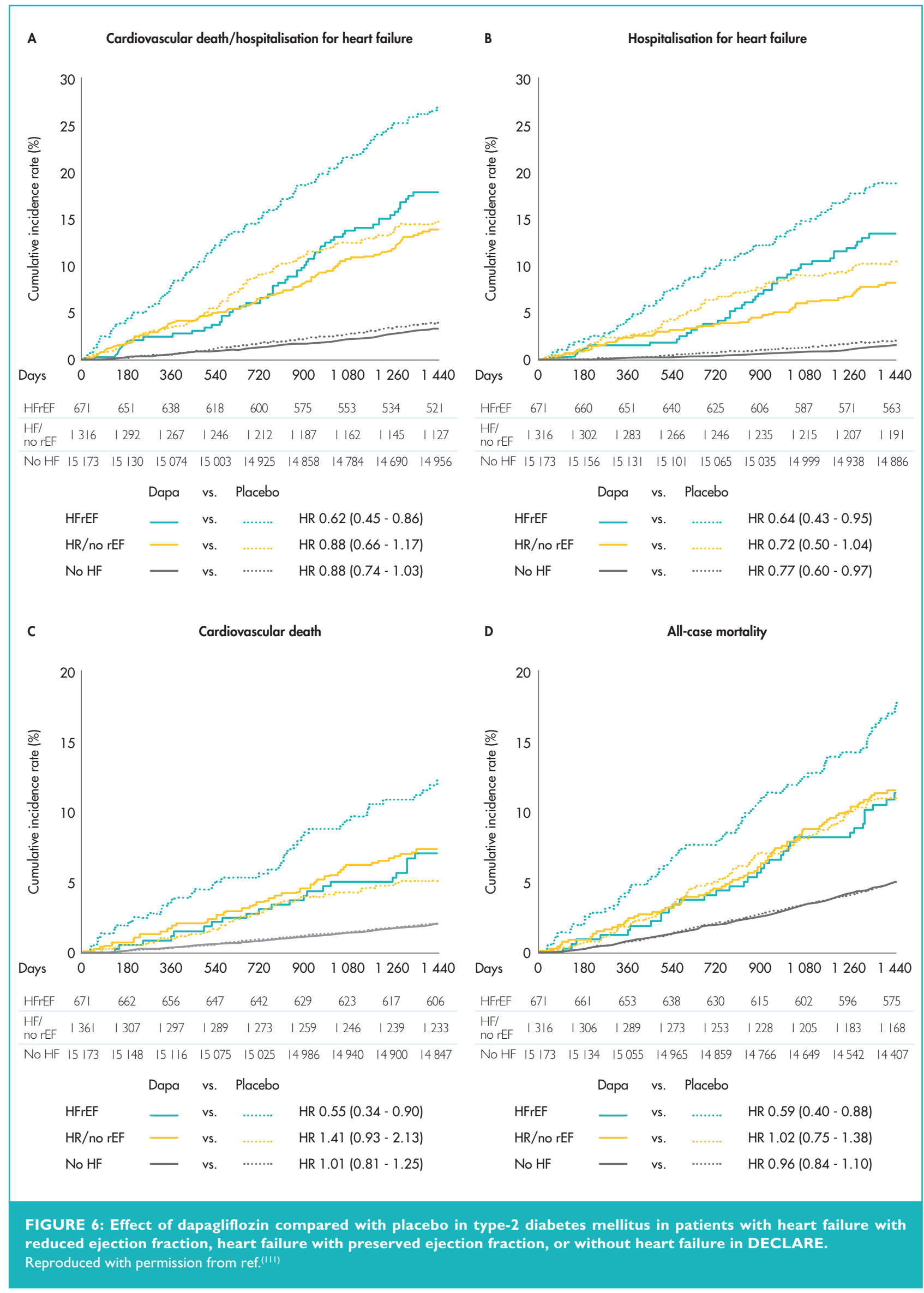




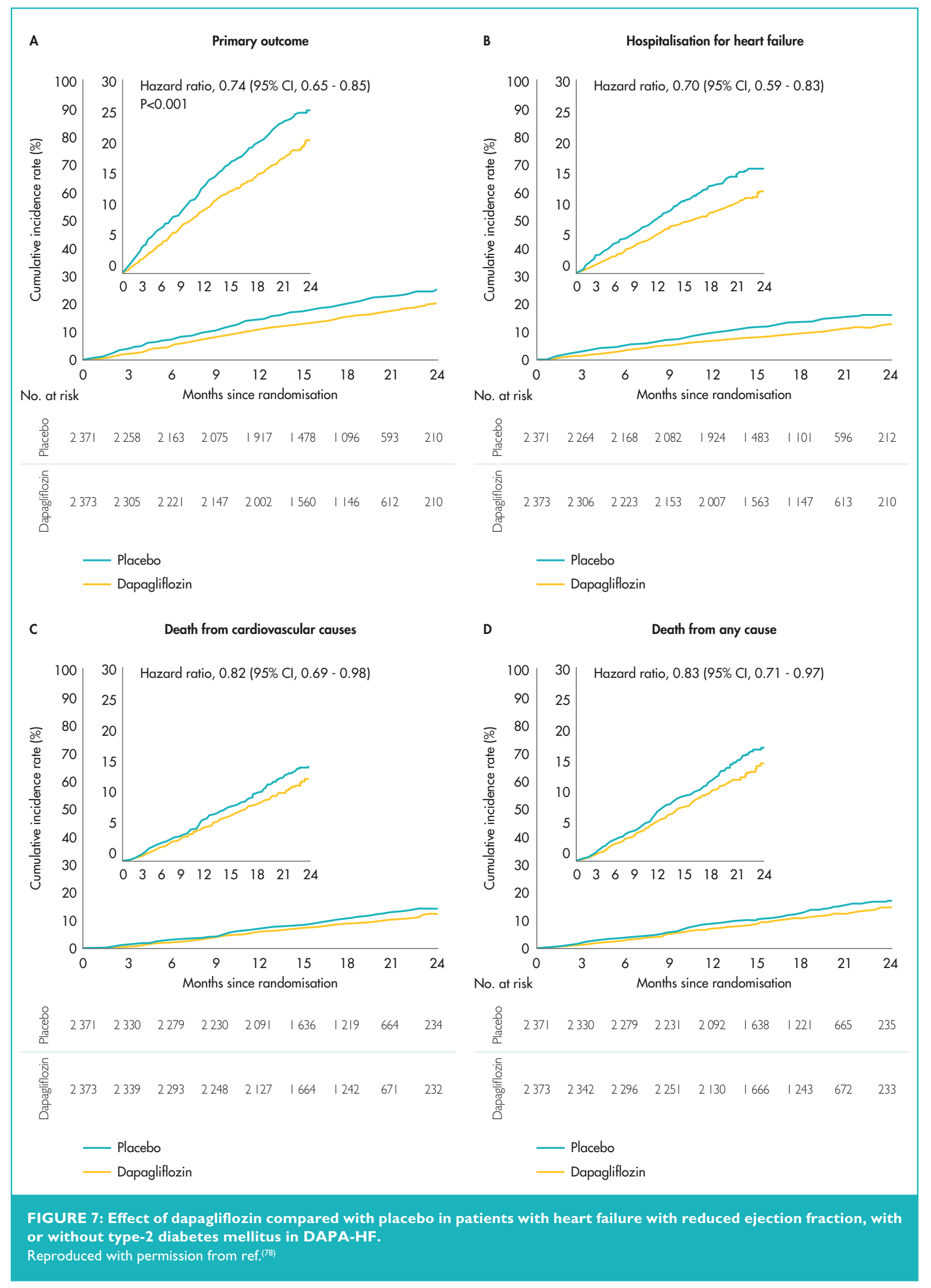


However, administration of exogenous erythropoietin did not reduce morbidity or mortality in the RED-HF trial.(118) Others have suggested that SGLT2i increase the production of ketones, which may be a more efficient myocardial energy substrate, or block myocardial sodium-hydrogen exchanger-3, which may improve myocardial function and reduce fibrosis. ${ }^{(119,120)}$ An RCT of empagliflozin in patients with T2DM but not heart failure ${ }^{(121)}$ suggested little effect on cardiac function or remodelling; RCTs of the effects of SGLT2i on cardiac function in patients with HFrEF and HFpEF are awaited. Future trials will confirm whether the benefit observed in DAPA-HF is a class effect and whether they are effective for HFpEF or when congestion is severe. ${ }^{(122,123)}$

\section{ACUTE HEART FAILURE}

Two large RCTs of serelaxin failed to confirm the results of the original RELAX-AHF trial. RELAX-AHF-EU,(124) an openlabel RCT $(n=2688)$, reported a similar and low rate for mortality $(\leq 2 \%)$ and re-admissions for heart failure $(<1 \%)$ at 14 days for patients assigned placebo or serelaxin, despite a reduction in worsening heart failure at day $5[6.7 \%-4.5 \%$ $(P<0.008)]$. The RELAX-AHF-2 trial, ${ }^{(125)}$ a double-blind RCT $(n=6545)$, reported that the rates of worsening heart failure in the first 5 days (about 7\%) and 180-day mortality (about 11\%) were similar for placebo and serelaxin. The failure of so many short-term interventions for AHF may reflect failed therapeutic concepts, ineffective interventions, or problems with trial design. RCTs of AHF are difficult to implement, especially if conducted double-blind. Indeed, GALACTIC, a trial of personalised, early intensive and sustained vasodilation with nitrates and hydralazine, also failed to show benefit, calling into question the concept of vasodilator therapy for the routine management of acute heart failure.(126) Many patients present with acute breathlessness in the middle of the night. It is difficult to have research staff available "24/7" when there is no "gateway" similar to a coronary care unit or catheter laboratory. Compassionate investigators may also be unwilling to enrol frail elderly patients who are most at risk of adverse outcomes. Moreover, breathlessness usually responds to oxygen and diuretics within hours, ${ }^{(127)}$ especially for patients with a systolic blood pressure $\geq 125 \mathrm{mmHg}$, as required in the serelaxin trials. On the other hand, patients with extensive peripheral oedema, ${ }^{(26)}$ renal dysfunction, and a low blood pressure, who often do not constitute an acute emergency have a poor prognosis and an unmet need for more effective interventions; pharmacological, or device. ${ }^{(127,128)}$

\section{STEM CELL THERAPY}

Intra-myocardial injection of stem cells failed to improve weaning from left ventricular assist devices. ${ }^{(130)}$

\section{HEART FAILURE IN PATIENTS WITH CANCER}

Interest in cardio-oncology reflects increasing survival after treatment for cancer, growing awareness of the CV toxicity associated with both established and new treatments for cancer, and interest in personalised risk-profiling prior to chemotherapy. People with cardiomyopathy-related gene mutations may be more prone $(7.5 \%$ of those with compared to $1.1 \%$ of those without a titin gene mutation) to develop ventricular dysfunction after the administration of chemotherapy. ${ }^{(131)}$ Interruption of trastuzumab is associated with a higher risk of cancer recurrence in women with early invasive HER2+ve breast cancer; about $60 \%$ of interruptions are for cardiotoxicity. (132) An observational study showed that of 30 women receiving HER2-targeted therapies who developed an LVEF of $40 \%$ - $49 \%$ and were treated prospectively with betablockers and ACE inhibitors, only 3 went on to develop severe heart failure or a LVEF $<35 \%$.(133) Cardiac function rarely returned to normal after completion of treatment, challenging the view that trastuzumab-related LV dysfunction is usually reversible. A recent study reported high rates of $C V$ events, especially heart failure, amongst patients with multiple myeloma receiving potent proteasome inhibitors, such as carfilzomib and bortezomib,(134) which were associated with much poorer survival. Risk factors for developing a CV event included elevated pre-treatment NT-proBNP or an increase during treatment. A systematic review of prophylactic use of reninangiotensin-aldosterone antagonists and beta-blockers identified 22 relevant RCTs, of which the largest had only 206 patients, ${ }^{(135,136)}$ but found no convincing evidence of clinical efficacy.

\section{IMPLEMENTATION OF THERAPY}

Analyses of administrative data from primary care in the UK suggest that implementation of therapy has improved substantially over the last decade, with $72 \%$ now prescribed a betablocker, although many patients remain on less than target doses. ${ }^{(6)}$ Among hospital discharges in England and Wales, $89 \%$ of those with HFrEF were discharged on a beta-blocker (https://www.nicor.org.uk/wp-content/uploads/2019/09/HeartFailure-2019-Report-final.pdf), which is very similar to that observed in patients with HFrEF selected for enrolment in the ESC-EURObservational Heart Failure Long-Term Registry.(137) However, an analysis of Medicare beneficiaries in the USA found that only $51 \%$ of patients with HFrEF were prescribed a beta-blocker after a first or recurrent hospitalisation for heart failure and only $12 \%$ received at least $\geq 50 \%$ of the target dose by one year. ${ }^{(138)}$ This suggests that the organisation of care for HFrEF makes an important difference to treatment and, consequently, outcome. However, a cluster RCT ( $n=2494)$ of service redesign aiming to improve hospital-to-home transition, which included self-care education, a structured hospital discharge summary, family physician follow-up within I week, and, 
for high-risk patients, home-visits, did not substantially improve patient wellbeing or outcome. ${ }^{(139)}$ An RCT $(n=110)$ showed that frequent (several times per month) visits to participating community pharmacies could improve medication adherence and wellbeing. (140) An RCT of 450 patients found benefits of e-Health intervention on self-care behaviour and quality of life in the first 3 months after initiation but not thereafter, ${ }^{(141)}$ with no effect on hospitalisations or mortality. There are many reasons why RCTs of complex interventions fail including inadequate power, suboptimal trial design, already excellent or unintended improvements in care for the control group, lack of long-term engagement and motivation of staff and patients, inclusion of patients for whom pharmacological intervention is largely ineffective (e.g. HFpEF), but sometimes we just have to admit that what should work does not. More evidence is required; learning from past experience. ${ }^{(142)}$

\section{REHABILITATION}

Systematic reviews suggest that exercise-based rehabilitation can improve patients' wellbeing and exercise capacity and reduce heart failure-related and all-cause hospitalisation, but may not reduce mortality, despite potentially improving adherence to treatment. ${ }^{(143-147)}$ The best and most cost-effective service-model is a topic of active research. ${ }^{(148,149)}$

\section{PALLIATIVE CARE}

Morphine relieves chronic breathlessness in patients with chronic lung disease, but data for heart failure are sparse. An RCT of 45 patients failed to demonstrate important clinical benefits of morphine administration to patients with HFrEF or HfpEF, predominantly in NYHA functional class III.(150)

\section{WITHDRAWING TREATMENT FOR HEART FAILURE AFTER RECOVERY}

Withdrawing treatment from patients with idiopathic or genetically determined dilated cardiomyopathy who have experienced full recovery of ventricular function should be done with great caution, if at all.(151) Although patients with a recovered LVEF (HFrcEF) may have a better prognosis, it may still not be good. ${ }^{(152)}$ Further research is required for peripartum and other specific types of cardiomyopathy. A recent report from an old trial (DIG), suggested that withdrawal of digoxin was associated with an increased risk of hospitalisation for heart failure but did not affect mortality. ${ }^{(153)}$ An RCT of I 88 patients with stable heart failure from Brazil suggested that $75 \%$ of patients could be withdrawn from loop diuretics for at least 90 days without deterioration in symptoms, need for reinstitution of diuretic therapy, or a rise in plasma NTproBNP. (154) This is in stark contrast to a smaller RCT from the UK, where withdrawal of diuretics and other therapies for 48 hours led to a doubling of plasma concentrations of
NT-proBNP, an increase in LV and left atrial volumes and worsening symptoms. ${ }^{(155)}$

\section{CONCLUSION}

Great progress in the understanding and management of heart failure has been made over the last year. New controversies and new evidence challenge many old assumptions. As ever, some will resist progress and others will embrace it. You, the reader, must help our professions and patients find the correct balance between reckless enthusiasm and diagnostic and therapeutic inertia.

\section{FUNDING}

The British Heart Foundation Cardiovascular Research Centre at the University of Glasgow is supported by a Centre of Research Excellence grant from the British Heart Foundation (RE/I8/6/34217).

Conflict of interest: Dr J.G.C. reports grants and personal fees from Amgen, Bayer, Novartis, Vifor, and Pharmacosmos; personal fees and non-financial support from Medtronic; personal fees from Abbott, outside the submitted work. Dr A.R.L. reports personal fees from Servier, Novartis, Roche, Takeda, Boehringer Ingelheim, Amgen, Clinigen Group, Ferring Pharmaceuticals, Eli Lily, Bristol Myers Squibb, and Eisai Ltd; grants and personal fees from Pfizer, outside the submitted work. T.M. reports honoraria from Vifor. J.J.M. reports non-financial support and other from AstraZeneca, during the conduct of the study; other from Bayer, non-financial support and other from Cardiorentis, non-financial support and other from Amgen, nonfinancial support and other from Oxford University/Bayer, nonfinancial support and other from Theracos, non-financial support and other from Abbvie, other from DalCor, other from Pfizer, other from Merck, non-financial support and other from Novartis, non-financial support and other from Glaxo Smith Kline (GSK), other from Bristol Myers Squibb (BMS), non-financial support and other from Vifor-Fresenius, nonfinancial support and other from Kidney Research UK (KRUK), non-financial support and other from Novartis, outside the submitted work. 


\section{REFERENCES}

1. Torabi A, Rigby AS, Cleland J. Declining in-hospital mortality and increasing heart failure incidence in elderly patients with first myocardial infarction. J Am Coll Cardiol 2009:55:79-8I.

2. Scirica BM, Braunwald E, Raz I, et al. Heart failure, saxagliptin, and diabetes mellitus: Observations from the SAVOR-TIMI 53 randomised trial. Circulation 2014;130:1579-1588.

3. Zhang $\mathrm{C}$, Jiang $\mathrm{L}, \mathrm{Xu} \mathrm{L}$, et al. Implications of $\mathrm{N}$-terminal pro-B-type natriuretic peptide in patients with three-vessel disease. Eur Heart J 2019;40: 3397-3405.

4. Cleland JGF, Pellicori P, Clark AL. Prevention or procrastination for heart failure? Why we need a universal definition of heart failure. J Am Coll Cardio 2019;73:2398-2400

5. Conrad N, Judge A, Canoy D, et al. Temporal trends and patterns in mortality after incident heart failure: A longitudinal analysis of 86000 individuals. JAMA Cardiol 2019;4:1 102

6. Conrad N, Judge A, Canoy D, et al. Diagnostic tests, drug prescriptions, and follow-up patterns after incident heart failure: A cohort study of 93000 UK patients. PLoS Med 20 19; I 6:el 002805.

7. Bottle A, Kim D, Aylin P, et al. Routes to diagnosis of heart failure: Observational study using linked data in England. Heart 20 I 8; 1 04:600-605.

8. Kim D, Hayhoe B, Aylin P, et al. Route to heart failure diagnosis in English primary care: A retrospective cohort study of variation. Br J Gen Pract 2019;69:e697-e705

9. Filippatos G, Angermann CE, Cleland JGF, et al. Global differences in acute heart failure patient characteristics, precipitants, point of hospital entry and inpatient management: An analysis from REPORT-HF, a worldwide, prospective heart failure disease registry. JAMA Cardiol 2019;in press.

10. Dokainish H, Teo K, Zhu J, et al.; INTER-CHF Investigators. Global mortality variations in patients with heart failure: Results from the Internationa Congestive Heart Failure (INTER-CHF) prospective cohort study. Lancet Glob Health 2017:5:e665-e672

I1. Dewan P, Rorth R, Jhund PS, et al. Income inequality and outcomes in heart failure: A global between-country analysis. JACC Heart Fail 2019;7:336-346.

12. Dewan $P$, Jhund $P S$, Shen $L$, et al. Heart failure with reduced ejection fraction: Comparison of patient characteristics and clinical outcomes within Asia and between Asia, Europe and the Americas. Eur J Heart Fail 2019;21:577-587.

13. Ferreira JP, Rossello X, Eschalier R, et al. MRAs in elderly HF patients: Individual patient-data meta-analysis of RALES, EMPAHSIS-HF, and TOPCAT. JACC Heart Fail 2019;7:1012-1021.

14. Ferreira JP, Rossignol P, Pizard A, et al. Potential spironolactone effects on collagen metabolism biomarkers in patients with uncontrolled blood pressure. Heart 2019; 105:307-314.

15. Pellicori P, Ferreira JP, Mariottoni B, et al. Effects of spironolactone on serum markers of fibrosis in people at high risk of developing heart failure: Rationale, design and baseline characteristics of a proof-of-concept, randomised, precision-medicine, prevention trial. The Heart OMics in AGing (HOMAGE) trial. Eur J Heart Failure 2019; in press.

16. Larsson SC, Back M, Rees JMB, et al. Body mass index and body composition in relation to 14 cardiovascular conditions in UK Biobank: A Mendelian randomisation study. Eur Heart J 2019;doi: I0.1093/eurheartj/ehz388.

17. Sillars A, Celis-Morales CA, Ho FK, et al. Association of fitness and grip strength with heart failure: Findings from the UK biobank population-based study. Mayo Clin Proc 2019;94:2230-2240.

18. Jamaly S, Carlsson L, Peltonen M, et al. Surgical obesity treatment and the risk of heart failure. Eur Heart J 2019;40:2131-2138.

19. Zhang J, Begley A, Jackson R, et al. Body mass index and all-cause mortality in heart failure patients with normal and reduced ventricular ejection fraction: A dose-response meta-analysis. Clin Res Cardiol 2019; I08: I | 9- 132.

20. Kytomaa S, Hegde S, Claggett B, et al. Association of influenza-like illness activity with hospitalisations for heart failure: The atherosclerosis risk in communities study. JAMA Cardiol 2019:4:363-369

21. Loeb M, Dokainish H, Dans A, et al. Randomised controlled trial of influenza vaccine in patients with heart failure to reduce adverse vascular events (IVVE): Rationale and design. Am Heart J 2019;212:36-44.
22. Liu L, Klein L, Eaton C, et al. Menopausal hormone therapy and risks of first hospitalised heart failure and its subtypes during the intervention and extended postintervention follow-up of the women's health initiative randomised trials. J Card Fail 2019;doi: I0.1016/j.cardfail.2019.09.006.

23. Pieske B, Tschope C, de Boer RA, et al. How to diagnose heart failure with preserved ejection fraction: The HFA-PEFF diagnostic algorithm: A consensus recommendation from the Heart Failure Association (HFA) of the European Society of Cardiology (ESC). Eur Heart J 2019;40:3297-3317.

24. Ho JE, Zern EK, Wooster L, et al. Differential clinical profiles, exercise responses, and outcomes associated with existing HFpEF definitions. Circulation 2019; 140:353-365.

25. Pellicori $P$, Shah P, Cuthbert J, et al. Prevalence, pattern and clinical relevance of ultrasound indices of congestion in outpatients with heart failure. Eur J Heart Fail 2019:21:904-916.

26. Shoaib A, Mamas MA, Ahmad QS, et al. Characteristics and outcome of acute heart failure patients according to the severity of peripheral oedema. Int J Cardiol 2019;285:40-46.

27. Shoaib A, Farag M, Nolan J, et al. Mode of presentation and mortality amongst patients hospitalised with heart failure? A report from the First Euro Heart Failure Survey. Clin Res Cardiol 2019;108:510-519.

28. Platz E, Solomon SD, McMurray J. Lung ultrasound: Monitoring congestion in patients with heart failure. Eur J Heart Fail 20 19;doi: I0.1002/ejhf. 636.

29. Platz E, Campbell RT, Claggett B, et al. Lung ultrasound in acute heart failure: Prevalence of pulmonary congestion and short- and long-term outcomes. JACC Heart Fail 2019;7:849-858.

30. Platz E, Jhund PS, Girerd N, et al.; on behalf of the Study Group on Acute Heart Failure of the Acute Cardiovascular Care Association and the Heart Failure Association of the European Society of Cardiology. Expert consensus document: Reporting checklist for quantification of pulmonary congestion by lung ultrasound in heart failure. Eur J Heart Fail 2019;21:844-851.

31. Pivetta E, Goffi A, Nazerian P, et al.; on behalf of the Study Group on Lung Ultrasound from the Molinette and Careggi Hospitals. Lung ultrasound integrated with clinical assessment for the diagnosis of acute decompensated heart failure in the emergency department: A randomised controlled trial. Eur J Heart Fail 2019;21:754-766.

32. Rivas-Lasarte M, Álvarez-García J, Fernández-Martínez J, et al. Lung ultrasound-guided treatment in ambulatory patients with heart failure: A randomised controlled clinical trial (LUS-HF study). Eur J Heart Fail 2019;doi: I0.1002/ejhf.I604.

33. Ter Maaten JM, Kremer D, Demissei BG, et al. Bio-adrenomedullin as a marker of congestion in patients with new-onset and worsening heart failure. Eur J Heart Fail 2019;21:732-743.

34. Abraham J, Bharmi $\mathrm{R}$, Jonsson $\mathrm{O}$, et al. Association of ambulatory haemodynamic monitoring of heart failure with clinical outcomes in a concurrent matched cohort analysis. JAMA Cardiol 2019;4:556-563.

35. Verbrugge $\mathrm{FH}$, Martens $\mathrm{P}$, Ameloot $\mathrm{K}$, et al. Acetazolamide to increase natriuresis in congestive heart failure at high risk for diuretic resistance. Eur J Heart Fail 2019:21:1415-1422.

36. Jones NR, Roalfe AK, Adoki I, et al. Survival of patients with chronic heart failure in the community: A systematic review and meta-analysis. Eur J Heart Fail 2019;21:1 306-1 325.

37. Kwok CS, Zieroth S, Van Spall HGC, et al. The Hospital Frailty Risk Score and its association with in-hospital mortality, cost, length of stay and discharge location in patients with heart failure short running title: Frailty and outcomes in heart failure. Int | Cardiol 20 I9;doi: | 0. I | | 6/j.jijcard.2019.09.064.

38. Savarese G, Dahlstrom U, Vasko P, et al. Association between reninangiotensin system inhibitor use and mortality/morbidity in elderly patients with heart failure with reduced ejection fraction: A prospective propensity score-matched cohort study. Eur Heart J 20 I 8;39:4257-4265.

39. Stolfo D, Uijl A, Benson L, et al. Association between beta-blocker use and mortality/morbidity in older patients with heart failure with reduced ejection fraction. A propensity score-matched analysis from the Swedish Heart Failure Registry. Eur J Heart Fail 2019;doi: 10.1002/ejhf.1615.

40. Rush CJ, Campbell RT, Jhund PS, et al. Association is not causation: Treatment effects cannot be estimated from observational data in heart failure. Eur Heart | 2018;39:3417-3438. 
41. Triposkiadis F, Butler J, Abboud FM, et al. The continuous heart failure spectrum: Moving beyond an ejection fraction classification. Eur Heart J 2019:40:2155-2163

42. De Boer RA, De KG, Bauersachs J, et al. Towards better definition, quantification and treatment of fibrosis in heart failure. A scientific roadmap by the Committee of Translational Research of the Heart Failure Association (HFA) of the European Society of Cardiology. Eur J Heart Fail 2019;21:272-285.

43. Packer $M$. The epicardial adipose inflammatory triad: Coronary atherosclerosis, atrial fibrillation, and heart failure with a preserved ejection fraction. Eur J Heart Fail 2018;20:1567-1569.

44. Pellicori P, Zhang J, Cuthbert J, et al. High sensitivity C-reactive protein in chronic heart failure: Patient characteristics, phenotypes and mode of death. Cardiovasc Res 2020; 1 16:91-100.

45. Tromp J, Ouwerkerk W, Demissei BG, et al. Novel endotypes in heart failure: Effects on guideline-directed medical therapy. Eur Heart J 2018;39:4269-4276

46. Kao DP, Lewsey JD, Anand IS, et al. Characterisation of subgroups of heart failure patients with preserved ejection fraction with possible implications for prognosis and treatment response. Eur J Heart Fail 20 15; 17:925-935.

47. Cao TH, Jones DJL, Voors AA, et al. Plasma proteomic approach in patients with heart failure: Insights into pathogenesis of disease progression and potential novel treatment targets. Eur J Heart Fail 2019;doi: 10.1002/ ejhf. 1608.

48. Cleland JGF, Van Veldhuisen DJ, Ponikowski P. The year in cardiology 2018 : Heart failure. Eur Heart J 2019;40:651-661.

49. Ponikowski P, Voors AA, Anker SD, et al. 2016 ESC Guidelines for the diagnosis and treatment of acute and chronic heart failure: The Task Force for the diagnosis and treatment of acute and chronic heart failure of the European Society of Cardiology (ESC) Developed with the special contribution of the Heart Failure Association (HFA) of the ESC. Eur Heart 2016;37:2129-2200

50. Wehner G], Jing L, Haggerty CM, et al. Routinely reported ejection fraction and mortality in clinical practice: Where does the nadir of risk lie? Eur Heart J 2019;doi: 10.1093/eurheartj/ehz550.

51. Seferovic PM, Ponikowski P, Anker SD, et al. Clinical practice update on heart failure 2019: Pharmacotherapy, procedures, devices and patient management. An expert consensus meeting report of The Heart Failure Association of the European Society of Cardiology. Eur J Heart Fail 2019;21:1169-1186

52. Obokata M, Reddy YNV, Melenovsky $V$, et al. Deterioration in right ventricular structure and function over time in patients with heart failure and preserved ejection fraction. Eur Heart J 2019;40:689-697.

53. Pellicori $P$, Urbinati $A$, Kaur $K$, et al. Prevalence and incidence of atrial fibrillation in ambulatory patients with heart failure. Am J Cardiol 2019 124:1554-1560.

54. Anderson SG, Shoaib A, Myint PK, et al. Does rhythm matter in acute heart failure? An insight from the British Society for Heart Failure National Audit. Clin Res Cardiol 2019;108:1276-1286.

55. Packer M. Effect of catheter ablation on pre-existing abnormalities of left atrial systolic, diastolic, and neurohormonal functions in patients with chronic heart failure and atrial fibrillation. Eur Heart J 2019;40:1873-1879.

56. Chen S, Purerfellner H, Meyer C, et al. Rhythm control for patients with atrial fibrillation complicated with heart failure in the contemporary era of catheter ablation: A stratified pooled analysis of randomised data. Eur Heart J 2019;doi: 10.1093/eurheartj/ehz443.

57. Barra S, Duehmke R, Providencia $R$, et al. Very long-term survival and late sudden cardiac death in cardiac resynchronisation therapy patients. Eur Heart J 2019:40:2121-2127.

58. Barra S, Providencia R, Narayanan K, et al. Time trends in sudden cardiac death risk in heart failure patients with cardiac resynchronisation therapy: A systematic review. Eur Heart J 2019;doi: 10.1093/eurheartj/ehz773.

59. Cleland JGF, Hindricks G, Petrie M. The shocking lack of evidence for implantable cardioverter defibrillators for heart failure; with or without cardiac resynchronisation. Eur Heart J 2019;40:2128-2130.
60. Halliday BP, Baksi AJ, Gulati A, et al. Outcome in dilated cardiomyopathy related to the extent, location, and pattern of late gadolinium enhancement. JACC Cardiovasc Imaging 2019;12:1645-1655.

61. Rorth R, Dewan P, Kristensen SL, et al. Efficacy of an implantable cardioverter-defibrillator in patients with diabetes and heart failure and reduced ejection fraction. Clin Res Cardiol 2019;108:868-877.

62. Rossello X, Ariti C, Pocock SJ, et al. Impact of mineralocorticoid receptor antagonists on the risk of sudden cardiac death in patients with heart failure and left-ventricular systolic dysfunction: An individual patient-level meta-analysis of 3 randomised-controlled trials. Clin Res Cardiol 2019; 108:477-486.

63. Nikolaidou T, Johnson MJ, Ghosh JM, et al. Postmortem ICD interrogation in mode of death classification. J Cardiovasc Electrophysiol 20। 8;29:573-583.

64. Leclercq C, Burri H, Curnis A, et al. Cardiac resynchronisation therapy nonresponder to responder conversion rate in the more response to cardiac resynchronisation therapy with MultiPoint Pacing (MORE-CRT MPP) study: Results from Phase I. Eur Heart J 2019:40:2979-2987.

65. Asch FM, Grayburn PA, Siegel RJ, et al. Echocardiographic outcomes after transcatheter leaflet approximation in patients with secondary mitral regurgitation: The COAPT trial. J Am Coll Cardiol 2019;74:2969-2979.

66. Baron SJ, Wang K, Arnold SV, et al.; On behalf of the COAPT Investigators. Cost-effectiveness of transcatheter mitral valve repair versus medical therapy in patients with heart failure and secondary mitral regurgitation: Results from the COAPT trial. Circulation 2019;140:1881-1891.

67. Arnold SV, Chinnakondepalli KM, Spertus JA, et al. Health status after transcatheter mitral-valve repair in heart failure and secondary mitral regurgitation: COAPT trial. J Am Coll Cardiol 2019;73:2123-2132.

68. Stone GW, Lindenfeld J, Abraham WT, et al. Transcatheter mitral-valve repair in patients with heart failure. N Engl J Med 20 8;379:2307-23।8.

69. lung B, Armoiry X, Vahanian A, et al.; on behalf of the MITRA-FR Investigators. Percutaneous repair or medical treatment for secondary mitral regurgitation: Outcomes at 2 years. Eur J Heart Fail 2019;doi: 10.1002/ejhf.1616.

70. Grayburn PA, Sannino A, Packer M. Proportionate and disproportionate functional mitral regurgitation: A new conceptual framework that reconciles the results of the MITRA-FR and COAPT trials. JACC Cardiovasc Imaging 2019;12:353-362.

7I. Packer M, Grayburn PA. Contrasting effects of pharmacological, procedural, and surgical interventions on proportionate and disproportionate functional mitral regurgitation in chronic heart failure. Circulation 20 I9; 140:779-789.

72. Witte KK, Lipiecki J, Siminiak T, et al. The REDUCE FMR trial: A randomised sham-controlled study of percutaneous mitral annuloplasty in functional mitral regurgitation. JACC Heart Fail 2019;7:945-955.

73. Nickenig G, Weber M, Lurz P, et al. Transcatheter edge-to-edge repair for reduction of tricuspid regurgitation: 6-month outcomes of the TRILUMINATE single-arm study. Lancet 2019;394:2002-201 I.

74. Taramasso M, Benfari G, van der Bijl P,et al. Transcatheter versus medical treatment of symptomatic severe tricuspid regurgitation. J Am Coll Cardiol 2019;74:2998-3008.

75. Branch KR, Probstfield JL, Eikelboom JW, et al. Rivaroxaban with or without aspirin in patients with heart failure and chronic coronary or peripheral artery disease: The COMPASS trial. Circulation 2019;140:529-537.

76. Cleland JGF, Pellicori P. Myocardial dysfunction and coronary artery disease as therapeutic targets in heart failure. Circulation 20।9;140:538-54I.

77. McMurray JJ, Packer M, Desai AS, et al. Angiotensin-neprilysin inhibition versus enalapril in heart failure. N Engl J Med 20 | 4;37|:993- 1004.

78. McMurray JJV, Solomon SD, Inzucchi SE, et al.; DAPA-HF Trial Committees and Investigators. Dapagliflozin in patients with heart failure and reduced ejection fraction. N Engl J Med 2019;381:1995-2008.

79. Greenberg B, Neaton JD, Anker SD, et al. Association of rivaroxaban with thromboembolic events in patients with heart failure, coronary disease, and sinus rhythm: A post hoc analysis of the COMMANDER HF trial. JAMA Cardiol 2019:4:515.

80. Mehra MR, Vaduganathan M, Fu M, et al. A comprehensive analysis of the effects of rivaroxaban on stroke or transient ischaemic attack in patients with heart failure, coronary artery disease, and sinus rhythm: The COMMANDER HF trial. Eur Heart J 2019;40:3593-3602. 


\section{REFERENCES}

81. Morrow DA, Velazquez EJ, DeVore AD, et al. Cardiovascular biomarkers in patients with acute decompensated heart failure randomised to sacubitril-valsartan or enalapril in the PIONEER-HF trial. Eur Heart J 2019; 40:3345-3352.

82. Wachter R, Senni M, Belohlavek J, et al. Initiation of sacubitril/valsartan in haemodynamically stabilised heart failure patients in hospital or early after discharge: Primary results of the randomised TRANSITION study. Eur Heart Fail 2019;21:998-1007

83. Desai AS, Solomon SD, Shah AM, et al. Effect of sacubitril-valsartan vs. enalapril on aortic stiffness in patients with heart failure and reduced ejection fraction: A randomised clinical trial. JAMA 2019;doi: 10.1001/jama. 2019.12843

84. Januzzi JL Jr, Prescott MF, Butler J, et al. Association of change in N-termina pro-B-type natriuretic peptide following initiation of sacubitril-valsartan treatment with cardiac structure and function in patients with heart failure with reduced ejection fraction. JAMA 2019;doi: 10.1001/jama.2019.12821.

85. Kang DH, Park SJ, Shin SH, et al. Angiotensin receptor neprilysin inhibitor for functional mitral regurgitation. Circulation 2019;139:1354-1365.

86. Zile MR, O'Meara E, Claggett B, et al. Effects of sacubitril/valsartan on biomarkers of extracellular matrix regulation in patients with HFrEF. J Am Coll Cardiol 2019;73:795-806.

87. Krum H, Elsik M, Schneider HG, et al. Relation of peripheral collagen markers to death and hospitalisation in patients with heart failure and preserved ejection fraction: Results of the I-PRESERVE collagen substudy. Circ Heart Fail 201 1;4:561-568

88. Solomon SD, Rizkala AR, Lefkowitz MP, et al. Baseline characteristics of patients with heart failure and preserved ejection fraction in the PARAGONHF trial. Circ Heart Fail 20 I 8; I : :e004962.

89. Cleland JGF, Tendera M, Adamus J, et al.; on behalf of PEP-CHF Investigators. The perindopril in elderly people with chronic heart failure (PEP-CHF) study. Eur Heart J 2006;27:2338-2345

90. Parthasarathy HK, Pieske B, Weisskopf M, et al. A randomised, double-blind, placebo-controlled study to determine the effects of valsartan on exercise time in patients with symptomatic heart failure with preserved ejection fraction. Eur J Heart Fail 2009; 1 1:980-989.

91. Solomon SD, McMurray JJV, Anand IS, et al. Angiotensin-neprilysin inhibition in heart failure with preserved ejection fraction. $N$ Engl J Med 2019; 381:1609-1620.

92. Beckett NS, Peters R, Fletcher AE, et al. Treatment of hypertension in patients 80 years of age or older. N Engl J Med 2008;358:1887-1898.

93. Solomon SD, Vaduganathan M, Claggett BL, et al. Sacubitril/valsartan across the spectrum of ejection fraction in heart failure. Circulation 2019; doi: 10.1 | 6 |/CIRCULATIONAHA. I 19.044586

94. McMurray JJV, Jackson AM, Lam CSP, et al. Effects of sacubitril-valsartan, versus valsartan, in women compared to men with heart failure and preserved ejection fraction: Insights from PARAGON-HF. Circulation 2019;doi: |0.1 |6 |/CIRCULATIONAHA. | 19.04449|

95. Vaduganathan M, Claggett BL, Desai AS, et al. Prior heart failure hospitalisation, clinical outcomes, and response to sacubitril/valsartan compared with valsartan in HFpEF. J Am Coll Cardiol 2019 Nov 6. pii: S07351097(19)38299-3. doi: 10.1016/j.jacc.2019.1 1.003. [Epub ahead of print].

96. Dewan P, Rorth R, Jhund PS, et al. Differential impact of heart failure with reduced ejection fraction on men and women. J Am Coll Cardiol 2019; 73:29-40.

97. Chandra A, Vaduganathan $M$, Lewis $E F$, et al. Health-related quality of life in heart failure with preserved ejection fraction: the PARAGON-HF trial. JACC Heart Fail 2019;7:862-874

98. Santema BT, Ouwerkerk W, Tromp J, et al. Identifying optimal doses of heart failure medications in men compared with women: A prospective, observational, cohort study. Lancet 2019;394:1254-1263.

99. Merrill M, Sweitzer NK, Lindenfeld J, et al. Sex differences in outcomes and responses to spironolactone in heart failure with preserved ejection fraction: A secondary analysis of TOPCAT trial. JACC Heart Fail 2019;7:228-238.

100. Linde C, Cleland JGF, Gold MR, et al. The interaction of sex, height, and QRS duration on the effects of cardiac resynchronisation therapy on morbidity and mortality: An individual-patient data meta-analysis. Eur J Heart Fail 20|8;20:780-79|.
101. Eickhoff MK, Dekkers CC], Kramers BJ, et al. Effects of dapagliflozin on volume status when added to renin-angiotensin system inhibitors. J Clin Med 2019;8:E779.

102. Dekkers CCJ, Sjostrom CD, Greasley PJ, et al. Effects of the sodium-glucose co-transporter-2 inhibitor dapagliflozin on estimated plasma volume in patients with type 2 diabetes. Diabetes Obes Metab 201 9;21:2667-2673.

103. Cefalo CMA, Cinti F, Moffa S, et al. Sotagliflozin, the first dual SGLT inhibitor: Current outlook and perspectives. Cardiovasc Diabetol 20। 9;18:20.

104. Zinman B, Wanner C, Lachin JM, et al. Empagliflozin, cardiovascular outcomes, and mortality in type 2 diabetes. N Engl J Med 2015;373:21 17-2 I28.

105. Yang DY, He X, Liang HW, et al. Comparative outcomes of heart failure among existent classes of anti-diabetic agents: A network meta-analysis of 171, 253 participants from 9| randomised controlled trials. Cardiovasc Diabetol 2019; 18:47.

106. Zelniker TA, Wiviott SD, Raz I, et al. Comparison of the effects of glucagonlike peptide receptor agonists and sodium-glucose cotransporter 2 inhibitors for prevention of major adverse cardiovascular and renal outcomes in type 2 diabetes mellitus. Circulation 2019;139:2022-2031.

107. Kristensen SL, Rorth R, Jhund PS, et al. Cardiovascular, mortality, and kidney outcomes with GLP-I receptor agonists in patients with type 2 diabetes: A systematic review and meta-analysis of cardiovascular outcome trials. Lancet Diabetes Endocrinol 2019:7:776-785.

108. Shen L, Rorth R, Cosmi D, et al. Insulin treatment and clinical outcomes in patients with diabetes and heart failure with preserved ejection fraction. Eur J Heart Fail 2019;21:974-984.

109. Zelniker TA, Wiviott SD, Raz I, et al. SGLT2 inhibitors for primary and secondary prevention of cardiovascular and renal outcomes in type 2 diabetes: A systematic review and meta-analysis of cardiovascular outcome trials. Lancet 2019;393:31-39.

1 10. Wiviott SD, Raz I, Bonaca MP, et al.; DECLARE-TIMI 58 Investigators. Dapagliflozin and cardiovascular outcomes in type 2 diabetes. N Engl J Med 2019;380:347-357.

III. Kato ET, Silverman MG, Mosenzon O, et al. Effect of dapagliflozin on heart failure and mortality in type 2 diabetes mellitus. Circulation 2019; 139:2528-2536.

I 12. McMurray JJV, DeMets DL, Inzucchi SE, et al.; on behalf of the DAPA-HF Committees and Investigators. The Dapagliflozin And Prevention of Adverse-outcomes in Heart Failure (DAPA-HF) trial: Baseline characteristics. Eur J Heart Fail 2019;21:1402-1411.

1 13. Martinez FA, Serenelli M, Nicolau JC, et al. Efficacy and safety of dapagliflozin in heart failure with reduced ejection fraction according to age: Insights from DAPA-HF. Circulation 20 I9; doi: 10.1 I6 I/CIRCULATIONAHA. I 19.044 I 33.

114. Kosiborod MN, Jhund P, Docherty KF, et al. Effects of dapagliflozin on symptoms, function and quality of life in patients with heart failure and reduced ejection fraction: Results from the DAPA-HF trial. Circulation 2019; doi: 10.1 161/CIRCULATIONAHA.119.044138.

1 15. Nassif ME, Windsor SL, Tang F, et al.; On behalf of the DEFINE-HF Investigators. Dapagliflozin effects on biomarkers, symptoms, and functional status in patients with heart failure with reduced ejection fraction: The DEFINE-HF trial. Circulation 2019; | 40: | 463- 1476.

I I6. Packer M, Anker SD, Butler J, et al. Effects of sodium-glucose cotransporter 2 inhibitors for the treatment of patients with heart failure: Proposal of a novel mechanism of action. JAMA Cardiol 2017;2:1025-1029.

1 17. Mazer CD, Hare GMT, Connelly PW, et al. Effect of empagliflozin on erythropoietin levels, iron stores and red blood cell morphology in patients with type 2 diabetes and coronary artery disease. Circulation 2019; doi: 10.1 161/CIRCULATIONAHA. I 19.044235.

I 18. Swedberg K, Young JB, Anand S, et al.; RED-HF Committees, RED-HF Investigators. Treatment of anemia with darbepoetin alfa in systolic heart failure. N Engl J Med 2013;368:1210-1219.

119. Packer M. Do sodium-glucose co-transporter-2 inhibitors prevent heart failure with a preserved ejection fraction by counterbalancing the effects of leptin? A novel hypothesis. Diabetes Obes Metab 20। 8;20:1361-1366.

120. Nielsen R, Møller N, Gormsen LC, et al. Cardiovascular effects of treatment with the ketone body 3-hydroxybutyrate in chronic heart failure patients. Circulation 2019;139:2129-2141. 
121. Verma S, Mazer CD, Yan AT, et al.; For the EMPA-HEART CardioLink-6 Investigators. Effect of empagliflozin on left ventricular mass in patients with type 2 diabetes mellitus and coronary artery disease: The EMPA-HEART cardiolink-6 randomised clinical trial. Circulation 2019;1 40:1693- 1702.

122. Packer M, Butler J, Filippatos GS, et al.; on behalf of the EMPEROR-Reduced Trial Committees and Investigators. Evaluation of the effect of sodiumglucose co-transporter 2 inhibition with empagliflozin on morbidity and mortality of patients with chronic heart failure and a reduced ejection fraction: Rationale for and design of the EMPEROR-Reduced trial. Eur J Heart Fail 2019;21:1270-1278.

123. Anker SD, Butler J, Filippatos GS, et al.; on behalf of the EMPEROR-Preserved Trial Committees and Investigators. Evaluation of the effects of sodiumglucose co-transporter 2 inhibition with empagliflozin on morbidity and mortality in patients with chronic heart failure and a preserved ejection fraction: Rationale for and design of the EMPEROR-Preserved Trial. Eur J Heart Fail 2019;21:1279-1287.

124. Maggioni AP, Lopez-Sendon J, Nielsen OW, et al. Efficacy and safety of serelaxin when added to standard of care in patients with acute heart failure: Results from a PROBE study, RELAX-AHF-EU. Eur J Heart Fail 2019;21:322-333.

125. Metra M, Teerlink JR, Cotter G, et al.; RELAX-AHF-2 Committees Investigators. Effects of serelaxin in patients with acute heart failure. N Engl Med 2019;381:716-726.

126. Kozhuharov N, Goudev A, Flores D, et al.; GALACTIC Investigators. Effect of a strategy of comprehensive vasodilation vs. usual care on mortality and heart failure rehospitalisation among patients with acute heart failure: The GALACTIC Randomised Clinical Trial. JAMA 2019;322:2292-2302.

127. Mebazaa A, Pang PS, Tavares M, et al. The impact of early standard therapy on dyspnoea in patients with acute heart failure: The URGENT-dyspnoea study. Eur Heart J 2010;31:832-841.

128. Biegus J, Zymlinski R, Siwolowski P, et al. Controlled decongestion by reprieve therapy in acute heart failure: Results of the TARGET-I and TARGET-2 studies. Eur J Heart Fail 2019;21:1079-1087.

129. Keeble TR, Karamasis GV, Rothman MT, et al. Percutaneous haemodynamic and renal support in patients presenting with decompensated heart failure: A multi-centre efficacy study using the Reitan Catheter Pump (RCP). Int J Cardiol 2019;275:53-58.

130. Yau TM, Pagani FD, Mancini DM, et al.; for the Cardiothoracic Surgical Trials Network. Intramyocardial injection of mesenchymal precursor cells and successful temporary weaning from left ventricular assist device support in patients with advanced heart failure: A randomised clinical trial. JAMA 2019 321:1176-1186.

131. Garcia-Pavia P, Kim Y, Restrepo-Cordoba MA, et al. Genetic variants associated with cancer therapy-induced cardiomyopathy. Circulation 2019;140:31-41.

132. Yu AF, Yadav NU, Lung BY, et al. Trastuzumab interruption and treatmentinduced cardiotoxicity in early HER2-positive breast cancer. Breast Cancer Res Treat 2015; | 49:489-495.

133. Lynce F, Barac A, Geng X, et al. Prospective evaluation of the cardiac safety of HER2-targeted therapies in patients with HER2-positive breast cancer and compromised heart function: The SAFE-HEaRt study. Breast Cancer Res Treat 2019;175:595-603

134. Cornell RF, Ky B, Weiss BM, et al. Prospective study of cardiac events during proteasome inhibitor therapy for relapsed multiple myeloma. J Clin Oncol 2019;37:1946-1955

135. Abuosa AM, Elshiekh AH, Qureshi K, et al. Prophylactic use of carvedilol to prevent ventricular dysfunction in patients with cancer treated with doxorubicin. Indian Heart J 2018;70(Suppl. 3):S96-S100.

136. Li X, Li Y, Zhang T, et al. Role of cardioprotective agents on chemotherapyinduced heart failure: A systematic review and network meta-analysis of randomised controlled trials. Pharmacol Res 2020; 151:104577.

137. Kapelios CJ, Lainscak M, Savarese G, et al. Sacubitril/valsartan eligibility and outcomes in the ESC-EORP-HFA Heart Failure Long-Term Registry: Bridging between European Medicines Agency/Food and Drug Administration label, the PARADIGM-HF trial, ESC guidelines, and real world. Eur J Heart Fail 2019;21:1383-1397.
138. Loop MS, van Dyke MK, Chen L, et al. Low utilisation of beta-blockers among medicare beneficiaries hospitalised for heart failure with reduced ejection fraction. J Card Fail 2019;25:343-35I.

139. Van Spall HGC, Lee SF, Xie F, et al. Effect of patient-centered transitional care services on clinical outcomes in patients hospitalised for heart failure: The PACT-HF randomised clinical trial. JAMA 2019;321:753-761.

140. Schulz M, Griese-Mammen N, Anker SD, et al.; for the PHARM-CHF Investigators. Pharmacy-based interdisciplinary intervention for patients with chronic heart failure: Results of the PHARM-CHF randomised controlled trial. Eur J Heart Fail 2019;21:1012-1021.

141. Wagenaar KP, Broekhuizen BDL, Jaarsma T, et al. Effectiveness of the European Society of Cardiology/Heart Failure Association website "heartfailurematters.org" and an e-health adjusted care pathway in patients with stable heart failure: Results of the "e-Vita HF" randomised controlled trial. Eur J Heart Fail 2019;21:238-246.

142. Shanbhag D, Graham ID, Harlos K, et al. Effectiveness of implementation interventions in improving physician adherence to guideline recommendations in heart failure: A systematic review. BMJ Open 20।8;8:e0I7765.

143. Taylor RS, Long L, Mordi IR, et al. Exercise-based rehabilitation for heart failure: Cochrane systematic review, meta-analysis, and trial sequential analysis. JACC Heart Fail 2019;7:691-705.

144. Taylor RS, Walker S, Smart NA, et al. Impact of exercise rehabilitation on exercise capacity and quality-of-life in heart failure: Individual participant meta-analysis. J Am Coll Cardiol 2019;73:1430-1443.

145. Taylor RS, Walker S, Smart NA, et al.; on behalf of the ExTraMATCH II Collaboration. Impact of exercise-based cardiac rehabilitation in patients with heart failure (ExTraMATCH II) on mortality and hospitalisation: An individual patient data meta-analysis of randomised trials. Eur J Heart Fail 2018:20:1735-1743.

146. Long L, Mordi IR, Bridges C, et al. Exercise-based cardiac rehabilitation for adults with heart failure. Cochrane Database Syst Rev 20 I9; I:CD003331.

147. Takeda A, Martin N, Taylor RS, et al. Disease management interventions for heart failure. Cochrane Database Syst Rev 2019;1:CD002752.

148. Taylor RS, Sadler S, Dalal HM, et al. The cost effectiveness of REACH-HF and home-based cardiac rehabilitation compared with the usual medical care for heart failure with reduced ejection fraction: A decision model-based analysis. Eur J Prev Cardiol 2019;26:1252-1261.

149. Wingham J, Frost J, Britten N, et al. Caregiver outcomes of the REACH-HF multicentre randomised controlled trial of home-based rehabilitation for heart failure with reduced ejection fraction. Eur J Cardiovasc Nurs 2019:18:611-620.

150. Johnson MJ, Cockayne S, Currow DC, et al. Oral modified release morphine for breathlessness in chronic heart failure: A randomised placebo-controlled trial. ESC Heart Fail 2019;doi: 10.1002/ehf2.12498.

151. Halliday BP, Wassall R, Lota AS, et al. Withdrawal of pharmacological treatment for heart failure in patients with recovered dilated cardiomyopathy (TRED-HF): An open-label, pilot, randomised trial. Lancet 2019;393:61-73.

152. Ghimire A, Fine N, Ezekowitz JA, et al. Frequency, predictors, and prognosis of ejection fraction improvement in heart failure: An echocardiogram-based registry study. Eur Heart J 2019;40:2110-2117.

153. Aguirre DL, Weber K, Bavendiek U, et al. Digoxin-mortality: Randomised vs. observational comparison in the DIG trial. Eur Heart J 2019:40:3336-334I.

154. Rohde LE, Rover MM, Figueiredo Neto JA, et al. Short-term diuretic withdrawal in stable outpatients with mild heart failure and no fluid retention receiving optimal therapy: A double-blind, multicentre, randomised trial. Eur Heart J 2019;40:3605-3612.

155. Dovancescu S, Pellicori P, Mabote T, et al. The effects of short-term omission of daily medication on the pathophysiology of heart failure. Eur J Heart Fail 2017; 19:643-649. 